\title{
Calonectria species isolated from Eucalyptus plantations and nurseries in South China
}

\author{
JieQiong Li ${ }^{1,2}$, Michael J. Wingfield², QianLi Liu ${ }^{1}$, Irene Barnes ${ }^{3}$, Jolanda Roux ${ }^{4}$, Lorenzo Lombard ${ }^{5}$, Pedro W. Crous ${ }^{2,5}$, and \\ ShuaiFei Chen ${ }^{1,2}$
}

\author{
${ }^{1}$ China Eucalypt Research Centre (CERC), Chinese Academy of Forestry (CAF), ZhanJiang 524022, GuangDong Province, China; corresponding \\ author e-mail: shuaifei.chen@gmail.com \\ ${ }^{2}$ Department of Microbiology and Plant Pathology, Forestry and Agricultural Biotechnology Institute (FABI), University of Pretoria, Pretoria, 0028, \\ South Africa \\ ${ }^{3}$ Department of Genetics, FABI, University of Pretoria, Pretoria 0028, South Africa \\ ${ }^{4}$ Department of Plant and Soil Sciences, FABI, University of Pretoria, Pretoria, 0028, South Africa \\ ${ }^{5}$ Westerdijk Fungal Biodiversity Institute, Uppsalalaan 8, 3584 CT Utrecht, The Netherlands
}

\begin{abstract}
Diseases caused by species of Calonectria (Ca.) represent a serious threat to the growth and sustainability of Eucalyptus plantations in China. Symptoms caused by these fungi mainly include leaf blight on trees in plantations and rotting of stems and leaves in nurseries. Extensive surveys have recently been conducted where Calonectria species were collected in Eucalyptus plantations and nurseries in the FuJian, GuangDong, GuangXi, and YunNan Provinces of South China. Additional isolates were baited from soil samples in the Hong Kong Region. The aim of this study was to identify the 115 Calonectria isolates obtained using comparisons of DNA sequence data for the $\beta$-tubulin (tub2), calmodulin ( $c m d A)$, histone $\mathrm{H} 3$ (his3) and partial translation elongation factor-1 $\alpha$ (tef1) gene regions as well as their morphological features. Seven known species were identified, including Calonectria arbusta, Ca. asiatica, Ca. chinensis, Ca. eucalypti, Ca. hongkongensis, Ca. mossambicensis and Ca. pentaseptata. In addition, six novel taxa were collected and are described here as $\mathrm{Ca}$. aciculata, $\mathrm{Ca}$. honghensis, Ca. lantauensis, Ca. pseudoturangicola, Ca. pseudoyunnanensis, and $\mathrm{Ca}$. yunnanensis spp. nov. Overall, the results reflect a high diversity of Calonectria species in China.
\end{abstract}

Article info: Submitted: 7 June 2017; Accepted: 1 October 2017; Published: 17 October 2017.

\section{INTRODUCTION}

The genus Calonectria (Hypocreales, Nectriaceae) includes numerous important pathogens that cause significant damage to a large number of herbaceous and woody plants worldwide (Crous 2002, Lombard et al. 2010a). Approximately 335 plant species residing in about 100 plant families are hosts to Calonectria species, including important plantation tree crops such as species of Eucalyptus, Pinus, and Acacia (Crous 2002, Lombard et al. 2010a). To date, at least 149 species of Calonectria have been described and verified based on comparisons of DNA sequence data (Lombard et al. 2016, Marin-Felix et al. 2017). Calonectria species are soil-borne fungi (Thies \& Patton 1970, Hwang \& Ko 1976, Gilligan 1983, Crous 2002) and disease symptoms resulting from infection include cutting rot, damping-off, leaf blight, red crown rot, root rot, seedling rot, shoot blight and stem canker (Crous et al. 1991, Brown \& Ferreira 2000, Crous 2002, Lombard et al. 2010a, 2015).

In China, plantation forestry utilizing rapidly-growing Eucalyptus species has expanded during the course of the
Key words: Cylindrocladium forest pathogens Nectriaceae phylogeny soil systematics

๑) 2017 International Mycological Association

You are free to share - to copy, distribute and transmit the work, under the following conditions:

Attribution: $\quad$ You must attribute the work in the manner specified by the author or licensor (but not in any way that suggests that they endorse you or your use of the work).

Non-commercial: $\quad$ You may not use this work for commercial purposes.

No derivative works: You may not alter, transform, or build upon this work.

For any reuse or distribution, you must make clear to others the license terms of this work, which can be found at http://creativecommons.org/licenses/by-nc-nd/3.0/legalcode. Any of the above conditions can be waived if you get permission from the copyright holder. Nothing in this license impairs or restricts the author's moral rights.

past two decades, to meet an increasing need for wood products. Approximately $4.5 \mathrm{M}$ ha of Eucalyptus plantations have been established in South China (Chen \& Chen 2013) and these are threatened by disease and insect pest problems (Zhou et al. 2008). Recent surveys of Eucalyptus plantations in South China have recorded several important emerging diseases, which include stem diseases caused by Teratosphaeria zuluensis (Cortinas et al. 2006, Chen et al. 2011a), species of Botryosphaeriaceae (Chen et al. 2011d) and Cryphonectriaceae (Chen et al. 2010, 2011b), and also Ceratocystis species (Chen et al. 2013). Leaf and shoot diseases caused by species of Mycosphaerellaceae and Teratosphaeriaceae (Burgess et al. 2006, 2007), Quambalaria species (Zhou et al. 2007), and Calonectria species (Crous et al. 2004, Lombard et al. 2010d, 2015, Chen et al. 2011c) have become widespread. Of these, Calonectria associated diseases are considered amongst the most threatening.

Pathogenic Calonectria species can cause significant losses to the Eucalyptus industry in China. The most important factor contributing to Calonectria infection and disease development is high humidity and free moisture (Crous 2002, 
Rodas et al. 2005). Common conditions in many parts of China where Eucalyptus species are propagated, serious disease problems emerge.

Twenty-eight species of Calonectria have been identified in China (Crous et al. 2004, Lombard et al. 2010d, 2015, Chen et al. 2011c, Xu et al. 2012). With the exception of Ca. nymphaeae (Xu et al. 2012), all species have been isolated from leaves, seedlings, and soil collected in Eucalyptus plantations and nurseries in South China (Supplementary Table 1). Twelve of these species were isolated from symptomatic Eucalyptus tissues, 17 were reported from soil associated with Eucalyptus trees or in Eucalyptus nurseries, and $\mathrm{Ca}$. pentaseptata and $\mathrm{Ca}$. terrestris were isolated from symptomatic Eucalyptus tissues as well as soil (Crous et al. 2004, Lombard et al. 2010d, 2015, Chen et al. 2011c). Pathogenicity tests have shown that 15 Calonectria species, including four known only from soil, are pathogenic to two tested $E$. urophylla $\times E$. grandis hybrid clones commonly planted in South China (Chen et al. 2011c, Li et al. 2014a, b). Nothing is known regarding the pathogenicity of the remaining 11 Calonectria species known only from soil (Supplementary Table 1).

Species of Calonectria are characterised by a sexual morph having yellow to dark red perithecia, scaly to warty ascomatal walls and 4-8-spored clavate asci. The asexual morphs produce branched conidiophores, cylindrical, septate conidia and stipe extensions with terminal vesicles of characteristic shape (Crous 2002, Lombard et al. 2010c, 2016). These asexual morphs provide the best diagnostic characters for identification, especially in conidial and vesicle morphology (Schoch et al. 2000, Crous 2002). Based on phylogenetic inference that matches with the distribution of vesicle shapes, species of Calonectria are divided into two main groups. These include the Prolate Group including species with clavate to pyriform to ellipsoidal vesicles and the Sphaero-Naviculate Group that accommodates species with sphaeropedunculate and naviculate vesicles (Lombard et al. 2010c). At present, 14 species of Calonectria found in China reside in the Prolate Group and these include four species complexes: the Ca. candelabrum complex (Ca. pauciramosa, Ca. seminaria, and $\mathrm{Ca}$. tetraramosa), Ca. colhounii complex (Ca. fujianensis, Ca. nymphaeae, and Ca. pseudocolhounii), Ca. cylindrospora complex (Ca. cerciana, Ca. foliicola, Ca. papillata, and $\mathrm{Ca}$. terrestris), and $\mathrm{Ca}$. reteaudii complex (Ca. crousiana, Ca. pentaseptata, Ca. microconidialis, and Ca. pseudoreteaudii) (Supplementary Table 1). The remaining 14 known species in China reside in the SphaeroNaviculate Group and they all cluster in the Ca. kyotensis complex (Crous et al. 2004, Lombard et al. 2010d, 2015, Chen et al. 2011c, Xu et al. 2012) (Supplementary Table 1).

Previous research has suggested a relatively high Calonectria species diversity in South China (Chen et al. 2011c, Lombard et al. 2015). This study was undertaken in order to provide a more comprehensive overview of Calonectria species associated with planted Eucalyptus in the provinces of South China.

\section{MATERIALS AND METHODS}

\section{Isolates}

Surveys for Calonectria species were conducted in Eucalyptus plantations and nurseries of the FuJian, GuangDong, GuangXi, and YunNan Provinces in South China (Table 1). Leaves on trees showing blight symptoms were collected in Eucalyptus plantations. In Eucalyptus nurseries, seedlings showing stem and leaf rot symptoms were selected. Soil in the Eucalyptus plantations, and soil samples or planting substrate in Eucalyptus nurseries, were also sampled. In addition, soil samples were collected in a naturally forested area on Lantau Island in Hong Kong (Table 1). At each sampling site, between five and 25 Eucalyptus trees or seedlings were sampled, and between 10 and 25 soil samples were collected between March 2014 and May 2015. The symptomatic tissues were incubated in moist chambers at room temperature for 1-7 d to induce Calonectria sporulation. Soil samples were baited with germinating Medicago sativa (alfalfa) seeds using the method described by Crous (2002).

Conidial masses were transferred directly from Eucalyptus or $M$. sativa infected tissues to $2 \%(\mathrm{v} / \mathrm{v})$ malt extract agar (MEA) under a AxioCam Stemi 2000C dissecting microscope (Carl Zeiss, Germany). After incubation at room temperature for 2-5 d, a single hyphal tip from each culture was transferred to MEA plates and incubated at room temperature for $1 \mathrm{wk}$ to obtain pure cultures.

Cultures were deposited in the Culture Collection of the China Eucalypt Research Centre (CERC), Chinese Academy of Forestry (CAF), ZhanJiang, GuangDong Province, China, and in the culture collection (CMW) of the Forestry Agricultural and Biotechnology Institute (FABI), University of Pretoria, Pretoria, South Africa. Representative isolates including the ex-type cultures were deposited in the culture collection (CBS) of the Westerdijk Fungal Biodiversity Institute, Utrecht, The Netherlands. Dried specimens of sporulating cultures were deposited in the National Collection of Fungi (PREM), Pretoria, South Africa.

\section{DNA extraction, PCR and sequence reactions}

Isolates from sampled trees, seedlings and soil representing all sampling sites were used for total genomic DNA extraction and sequence comparisons. The DNA was extracted from 5-7-d-old cultures, using the CTAB method " 5 " as described by Van Burik et al. (1998). DNA concentrations were determined using a NanoDrop ND-2000 Spectrometer (Thermo Fisher Scientific, Waltham, MA). Four gene regions including the partial $\beta$-tubulin (tub2), calmodulin (cmdA), histone $\mathrm{H} 3$ (his3) and translation elongation factor 1-alpha (tef1) were amplified using the primers and protocols described by Lombard et al. (2010c). The TopTaqTM Master Mix Kit (Qiagen, Hilden) was used to amplify these gene regions. All PCR products were sequenced in both directions, using the same primers used for PCR amplification by the Beijing Genomics Institution, Guangzhou, China. All sequences obtained in this study were edited using Geneious v. 7.0 (Kearse et al. 2012) and were deposited in GenBank (Table 1).

\section{Phylogenetic analyses}

All sequences representing the different Calonectria species in this study were used together with published 
Table 1. Species of Calonectria collected in this study.

\begin{tabular}{|c|c|c|c|c|c|c|c|c|c|}
\hline \multirow[t]{2}{*}{ Species $^{1}$} & \multirow[t]{2}{*}{ Isolate No. ${ }^{2}$} & \multirow[t]{2}{*}{ Haplotype $^{3}$} & \multirow[t]{2}{*}{ Substrate } & \multirow[t]{2}{*}{ Sampling site } & \multirow[t]{2}{*}{ Collector } & \multicolumn{4}{|c|}{ GenBank accession No. ${ }^{4}$} \\
\hline & & & & & & tef1 & his3 & cmdA & tub2 \\
\hline Ca. aciculata & $\begin{array}{l}\text { CMW 47645 5-8; CERC } \\
\text { 5342; CBS } 142883\end{array}$ & AAAA & $\begin{array}{l}\text { Eucalyptus urophylla } \times E \text {. } \\
\text { grandis leaf in plantation }\end{array}$ & $\begin{array}{l}\text { WeiYuan, JingGu, PuEr, } \\
\text { YunNan, China }\end{array}$ & $\begin{array}{l}\text { S.F. Chen, J.Q. Li \& } \\
\text { G.Q. Li }\end{array}$ & MF442644 & MF442759 & MF442874 & MF442989 \\
\hline \multirow[t]{11}{*}{ Ca. arbusta } & $\begin{array}{l}\text { CMW 47502; CERC } \\
9516\end{array}$ & AAA-9 & Soil in Eucalyptus plantation & $\begin{array}{l}\text { XiaoPingYang, XingBin, } \\
\text { LaiBin, GuangXi, China }\end{array}$ & S.B. Liang & MF442645 & MF442760 & MF442875 & - \\
\hline & $\begin{array}{l}\text { CMW 47503; CERC } \\
9520\end{array}$ & AAA- & Soil in Eucalyptus plantation & $\begin{array}{l}\text { XiaoPingYang, XingBin, } \\
\text { LaiBin, GuangXi, China }\end{array}$ & S.B. Liang & MF442646 & MF442761 & MF442876 & - \\
\hline & $\begin{array}{l}\text { CMW 47504; CERC } \\
9522\end{array}$ & AAA- & Soil in Eucalyptus plantation & $\begin{array}{l}\text { XiaoPingYang, XingBin, } \\
\text { LaiBin, GuangXi, China }\end{array}$ & S.B. Liang & MF442647 & MF442762 & MF442877 & - \\
\hline & $\begin{array}{l}\text { CMW 47505; CERC } \\
9523\end{array}$ & AAA- & Soil in Eucalyptus plantation & $\begin{array}{l}\text { XiaoPingYang, XingBin, } \\
\text { LaiBin, GuangXi, China }\end{array}$ & S.B. Liang & MF442648 & MF442763 & MF442878 & - \\
\hline & $\begin{array}{l}\text { CMW 47506; CERC } \\
9525\end{array}$ & AAA- & Soil in Eucalyptus plantation & $\begin{array}{l}\text { XiaoPingYang, XingBin, } \\
\text { LaiBin, GuangXi, China }\end{array}$ & S.B. Liang & MF442649 & MF442764 & MF442879 & - \\
\hline & $\begin{array}{l}\text { CMW 47507; CERC } \\
9526\end{array}$ & AAA- & Soil in Eucalyptus plantation & $\begin{array}{l}\text { XiaoPingYang, XingBin, } \\
\text { LaiBin, GuangXi, China }\end{array}$ & S.B. Liang & MF442650 & MF442765 & MF442880 & - \\
\hline & $\begin{array}{l}\text { CMW 475085; CERC } \\
9527\end{array}$ & AAA- & Soil in Eucalyptus plantation & $\begin{array}{l}\text { XiaoPingYang, XingBin, } \\
\text { LaiBin, GuangXi, China }\end{array}$ & S.B. Liang & MF442651 & MF442766 & MF442881 & - \\
\hline & $\begin{array}{l}\text { CMW 47509; CERC } \\
9528\end{array}$ & AAA- & Soil in Eucalyptus plantation & $\begin{array}{l}\text { XiaoPingYang, XingBin, } \\
\text { LaiBin, GuangXi, China }\end{array}$ & S.B. Liang & MF442652 & MF442767 & MF442882 & - \\
\hline & $\begin{array}{l}\text { CMW 476375; CERC } \\
5320\end{array}$ & AAA- & Soil in Eucalyptus plantation & $\begin{array}{l}\text { XiDi, LongXu, WuZhou, } \\
\text { GuangXi, China }\end{array}$ & $\begin{array}{l}\text { S.F. Chen, J.Q. Li } \\
\text { \& W. Lu }\end{array}$ & MF442653 & MF442768 & MF442883 & - \\
\hline & $\begin{array}{l}\text { CMW 47638; CERC } \\
5322\end{array}$ & AAA- & Soil in Eucalyptus plantation & $\begin{array}{l}\text { XiDi, LongXu, WuZhou, } \\
\text { GuangXi, China }\end{array}$ & $\begin{array}{l}\text { S.F. Chen, J.Q. Li } \\
\text { \& W. Lu }\end{array}$ & MF442654 & MF442769 & MF442884 & - \\
\hline & $\begin{array}{l}\text { CMW 47639; CERC } \\
5324\end{array}$ & AAA- & Soil in Eucalyptus plantation & $\begin{array}{l}\text { XiDi, LongXu, WuZhou, } \\
\text { GuangXi, China }\end{array}$ & $\begin{array}{l}\text { S.F. Chen, J.Q. Li } \\
\text { \& W. Lu }\end{array}$ & MF442655 & MF442770 & MF442885 & - \\
\hline \multirow[t]{2}{*}{ Ca. asiatica } & $\begin{array}{l}\text { CMW 476415; CERC } \\
5333\end{array}$ & AAA- & Soil in Eucalyptus plantation & $\begin{array}{l}\text { ZhengXing, JingGu, } \\
\text { PuEr, YunNan, China }\end{array}$ & $\begin{array}{l}\text { S.F. Chen, J.Q. Li \& } \\
\text { G.Q. Li }\end{array}$ & MF442656 & MF442771 & MF442886 & - \\
\hline & $\begin{array}{l}\text { CMW 476545; CERC } \\
5373\end{array}$ & ABB- & Soil in Eucalyptus plantation & $\begin{array}{l}\text { WeiYuan, JingGu, PuEr, } \\
\text { YunNan, China }\end{array}$ & $\begin{array}{l}\text { S.F. Chen, J.Q. Li \& } \\
\text { G.Q. Li }\end{array}$ & MF442657 & MF442772 & MF442887 & - \\
\hline \multirow[t]{4}{*}{ Ca. chinensis } & $\begin{array}{l}\text { CMW 472565; CERC } \\
3339\end{array}$ & AAAA & Soil & $\begin{array}{l}\text { Lantau, Lidao, Hong } \\
\text { Kong, China }\end{array}$ & $\begin{array}{l}\text { M.J. Wingfield \& } \\
\text { S.F. Chen }\end{array}$ & MF442658 & MF442773 & MF442888 & MF442990 \\
\hline & $\begin{array}{l}\text { CMW 472585; CERC } \\
3349\end{array}$ & ABAA & Soil & $\begin{array}{l}\text { Lantau, Lidao, Hong } \\
\text { Kong, China }\end{array}$ & $\begin{array}{l}\text { M.J. Wingfield \& } \\
\text { S.F. Chen }\end{array}$ & MF442659 & MF442774 & MF442889 & MF442991 \\
\hline & $\begin{array}{l}\text { CMW 472595; CERC } \\
3350\end{array}$ & ABAA & Soil & $\begin{array}{l}\text { Lantau, Lidao, Hong } \\
\text { Kong, China }\end{array}$ & $\begin{array}{l}\text { M.J. Wingfield \& } \\
\text { S.F. Chen }\end{array}$ & MF442660 & MF442775 & MF442890 & MF442992 \\
\hline & $\begin{array}{l}\text { CMW 47260; CERC } \\
3351\end{array}$ & ABAA & Soil & $\begin{array}{l}\text { Lantau, Lidao, Hong } \\
\text { Kong, China }\end{array}$ & $\begin{array}{l}\text { M.J. Wingfield \& } \\
\text { S.F. Chen }\end{array}$ & MF442661 & MF442776 & MF442891 & MF442993 \\
\hline
\end{tabular}


Table 1. (Continued).

\begin{tabular}{|c|c|c|c|c|c|c|c|c|c|}
\hline \multirow[t]{2}{*}{ Species $^{1}$} & \multirow[t]{2}{*}{ Isolate No. ${ }^{2}$} & \multirow[t]{2}{*}{ Haplotype $^{3}$} & \multirow[t]{2}{*}{ Substrate } & \multirow[t]{2}{*}{ Sampling site } & \multirow[t]{2}{*}{ Collector } & \multicolumn{4}{|c|}{ GenBank accession No. ${ }^{4}$} \\
\hline & & & & & & tef1 & his3 & $c m d A$ & tub2 \\
\hline Ca. eucalypti & $\begin{array}{l}\text { CMW 476605; CERC } \\
5401\end{array}$ & AAAA & $\begin{array}{l}\text { E. urophylla } \times E \text {. grandis leaf } \\
\text { in plantation }\end{array}$ & $\begin{array}{l}\text { WeiYuan, JingGu, PuEr, } \\
\text { YunNan, China }\end{array}$ & $\begin{array}{l}\text { S.F. Chen, J.Q. Li \& } \\
\text { G.Q. Li }\end{array}$ & MF442662 & MF442777 & MF442892 & MF442994 \\
\hline \multirow[t]{5}{*}{ Ca. honghensis } & $\begin{array}{l}\text { CMW 476675; CERC } \\
5568\end{array}$ & AAAA & Soil in Eucalyptus plantation & $\begin{array}{l}\text { XinXian, PingBian, } \\
\text { HongHe, YunNan, China }\end{array}$ & $\begin{array}{l}\text { S.F. Chen, J.Q. Li \& } \\
\text { G.Q. Li }\end{array}$ & MF442663 & MF442778 & MF442893 & MF442995 \\
\hline & $\begin{array}{l}\text { CMW 476685-7; CERC } \\
\text { 5571; CBS } 142884\end{array}$ & AAAA & Soil in Eucalyptus plantation & $\begin{array}{l}\text { XinXian, PingBian, } \\
\text { HongHe, YunNan, China }\end{array}$ & $\begin{array}{l}\text { S.F. Chen, J.Q. Li \& } \\
\text { G.Q. Li }\end{array}$ & MF442664 & MF442779 & MF442894 & MF442996 \\
\hline & $\begin{array}{l}\text { CMW 476695-8; CERC } \\
\text { 5572; CBS 142885 }\end{array}$ & AAAA & Soil in Eucalyptus plantation & $\begin{array}{l}\text { XinXian, PingBian, } \\
\text { HongHe, YunNan, China }\end{array}$ & $\begin{array}{l}\text { S.F. Chen, J.Q. Li \& } \\
\text { G.Q. Li }\end{array}$ & MF442665 & MF442780 & MF442895 & MF442997 \\
\hline & $\begin{array}{l}\text { CMW 476705-7; CERC } \\
\text { 5573; CBS 142886 }\end{array}$ & AAAA & Soil in Eucalyptus plantation & $\begin{array}{l}\text { XinXian, PingBian, } \\
\text { HongHe, YunNan, China }\end{array}$ & $\begin{array}{l}\text { S.F. Chen, J.Q. Li \& } \\
\text { G.Q. Li }\end{array}$ & MF442666 & MF442781 & MF442896 & MF442998 \\
\hline & $\begin{array}{l}\text { CMW 476715; CERC } \\
5574\end{array}$ & AAAA & Soil in Eucalyptus plantation & $\begin{array}{l}\text { XinXian, PingBian, } \\
\text { HongHe, YunNan, China }\end{array}$ & $\begin{array}{l}\text { S.F. Chen, J.Q. Li \& } \\
\text { G.Q. Li }\end{array}$ & MF442667 & MF442782 & MF442897 & MF442999 \\
\hline \multirow[t]{8}{*}{ Ca. hongkongensis } & $\begin{array}{l}\text { CMW 472575; CERC } \\
3341\end{array}$ & AAAA & Soil & $\begin{array}{l}\text { Lantau, Lidao, Hong } \\
\text { Kong, China }\end{array}$ & $\begin{array}{l}\text { M.J. Wingfield \& } \\
\text { S.F. Chen }\end{array}$ & MF442668 & MF442783 & MF442898 & MF443000 \\
\hline & $\begin{array}{l}\text { CMW 47271; CERC } \\
3570\end{array}$ & AAAA & Soil in Eucalyptus plantation & $\begin{array}{l}\text { ChangLe, HePu, BeiHai, } \\
\text { GuangXi, China }\end{array}$ & $\begin{array}{l}\text { S.F. Chen, J.Q. Li \& } \\
\text { G.Q. Li }\end{array}$ & MF442669 & MF442784 & MF442899 & MF443001 \\
\hline & $\begin{array}{l}\text { CMW 472745; CERC } \\
3573\end{array}$ & AAAA & Soil in Eucalyptus plantation & $\begin{array}{l}\text { ChangLe, HePu, BeiHai, } \\
\text { GuangXi, China }\end{array}$ & $\begin{array}{l}\text { S.F. Chen, J.Q. Li \& } \\
\text { G.Q. Li }\end{array}$ & MF442670 & MF442785 & MF442900 & MF443002 \\
\hline & $\begin{array}{l}\text { CMW 47495; CERC } \\
7125\end{array}$ & AAAA & Soil & $\begin{array}{l}\text { FAFU, CangShan, } \\
\text { FuZhou, FuJian, China }\end{array}$ & S.F. Chen & MF442671 & MF442786 & MF442901 & MF443003 \\
\hline & $\begin{array}{l}\text { CMW 47499; CERC } \\
7132\end{array}$ & AAAA & Soil & $\begin{array}{l}\text { FAFU, CangShan, } \\
\text { FuZhou, FuJian, China }\end{array}$ & S.F. Chen & MF442672 & MF442787 & MF442902 & MF443004 \\
\hline & $\begin{array}{l}\text { CMW 47500; CERC } \\
7133\end{array}$ & AAAA & Soil & $\begin{array}{l}\text { FAFU, CangShan, } \\
\text { FuZhou, FuJian, China }\end{array}$ & S.F. Chen & MF442673 & MF442788 & MF442903 & MF443005 \\
\hline & $\begin{array}{l}\text { CMW 47501; CERC } \\
7137\end{array}$ & AAAA & Soil & $\begin{array}{l}\text { FAFU, CangShan, } \\
\text { FuZhou, FuJian, China }\end{array}$ & S.F. Chen & MF442674 & MF442789 & MF442904 & MF443006 \\
\hline & $\begin{array}{l}\text { CMW 47619; CERC } \\
3288\end{array}$ & AAAA & Soil & $\begin{array}{l}\text { Lantau, Lidao, Hong } \\
\text { Kong, China }\end{array}$ & $\begin{array}{l}\text { M.J. Wingfield \& } \\
\text { S.F. Chen }\end{array}$ & MF442675 & MF442790 & MF442905 & MF443007 \\
\hline \multirow[t]{2}{*}{ Ca. lantauensis } & $\begin{array}{l}\text { CMW 47251 5-7; CERC } \\
3301 ; \text { CBS } 142887\end{array}$ & AAA- & Soil & $\begin{array}{l}\text { Lantau, Lidao, Hong } \\
\text { Kong, China }\end{array}$ & $\begin{array}{l}\text { M.J. Wingfield \& } \\
\text { S.F. Chen }\end{array}$ & MF442676 & MF442791 & MF442906 & - \\
\hline & $\begin{array}{l}\text { CMW 472525-8; CERC } \\
\text { 3302; CBS } 142888\end{array}$ & AAA- & Soil & $\begin{array}{l}\text { Lantau, Lidao, Hong } \\
\text { Kong, China }\end{array}$ & $\begin{array}{l}\text { M.J. Wingfield \& } \\
\text { S.F. Chen }\end{array}$ & MF442677 & MF442792 & MF442907 & - \\
\hline \multirow[t]{2}{*}{ Ca. mossambicensis } & $\begin{array}{l}\text { CMW 474655; CERC } \\
6979\end{array}$ & AAAA & $\begin{array}{l}\text { Medium of } E \text {. urophylla } \times E \text {. } \\
\text { grandis seedling in nursery }\end{array}$ & $\begin{array}{l}\text { LingBei, SuiXi, } \\
\text { ZhanJiang, GuangDong, } \\
\text { China }\end{array}$ & $\begin{array}{l}\text { S.F. Chen, J.Q. Li \& } \\
\text { G.Q. Li }\end{array}$ & MF442678 & MF442793 & MF442908 & MF443008 \\
\hline & $\begin{array}{l}\text { CMW 47466; CERC } \\
6990\end{array}$ & AAAA & $\begin{array}{l}\text { Medium of } E \text {. urophylla } \times E \text {. } \\
\text { grandis seedling in nursery }\end{array}$ & $\begin{array}{l}\text { LingBei, SuiXi, } \\
\text { ZhanJiang, GuangDong, } \\
\text { China }\end{array}$ & $\begin{array}{l}\text { S.F. Chen, J.Q. Li \& } \\
\text { G.Q. Li }\end{array}$ & MF442679 & MF442794 & MF442909 & MF443009 \\
\hline
\end{tabular}




\begin{tabular}{|c|c|c|c|c|c|c|c|c|c|}
\hline \multirow[t]{2}{*}{ Species $^{1}$} & \multirow[t]{2}{*}{ Isolate No. ${ }^{2}$} & \multirow[t]{2}{*}{ Haplotype $^{3}$} & \multirow[t]{2}{*}{ Substrate } & \multirow[t]{2}{*}{ Sampling site } & \multirow[t]{2}{*}{ Collector } & \multicolumn{4}{|c|}{ GenBank accession No. ${ }^{4}$} \\
\hline & & & & & & tef1 & his3 & $c m d A$ & tub2 \\
\hline & $\begin{array}{l}\text { CMW 47467; CERC } \\
6996\end{array}$ & AAAA & $\begin{array}{l}\text { E. urophylla } \times E \text {. grandis } \\
\text { seedling stem in nursery }\end{array}$ & $\begin{array}{l}\text { LingBei, SuiXi, } \\
\text { ZhanJiang, GuangDong, } \\
\text { China }\end{array}$ & $\begin{array}{l}\text { S.F. Chen, J.Q. Li \& } \\
\text { G.Q. Li }\end{array}$ & MF442680 & MF442795 & MF442910 & MF443010 \\
\hline & $\begin{array}{l}\text { CMW 47469; CERC } \\
7004\end{array}$ & AAAA & $\begin{array}{l}\text { E. urophylla } \times E \text {. grandis } \\
\text { seedling stem in nursery }\end{array}$ & $\begin{array}{l}\text { LingBei, SuiXi, } \\
\text { ZhanJiang, GuangDong, } \\
\text { China }\end{array}$ & $\begin{array}{l}\text { S.F. Chen, J.Q. Li \& } \\
\text { G.Q. Li }\end{array}$ & MF442681 & MF442796 & MF442911 & MF443011 \\
\hline & $\begin{array}{l}\text { CMW 47472; CERC } \\
7022\end{array}$ & AAAA & $\begin{array}{l}\text { E. urophylla } \times E \text {. grandis } \\
\text { seedling stem in nursery }\end{array}$ & $\begin{array}{l}\text { LingBei, SuiXi, } \\
\text { ZhanJiang, GuangDong, } \\
\text { China }\end{array}$ & $\begin{array}{l}\text { S.F. Chen, J.Q. Li \& } \\
\text { G.Q. Li }\end{array}$ & MF442682 & MF442797 & MF442912 & MF443012 \\
\hline & $\begin{array}{l}\text { CMW 47476; CERC } \\
7038\end{array}$ & AAAA & $\begin{array}{l}\text { E. urophylla } \times E \text {. grandis } \\
\text { seedling stem in nursery }\end{array}$ & $\begin{array}{l}\text { LingBei, SuiXi, } \\
\text { ZhanJiang, GuangDong, } \\
\text { China }\end{array}$ & $\begin{array}{l}\text { S.F. Chen, J.Q. Li \& } \\
\text { G.Q. Li }\end{array}$ & MF442683 & MF442798 & MF442913 & MF443013 \\
\hline & $\begin{array}{l}\text { CMW 47478; CERC } \\
7048\end{array}$ & AAAA & $\begin{array}{l}\text { E. urophylla } \times \text { E. grandis } \\
\text { seedling stem in nursery }\end{array}$ & $\begin{array}{l}\text { LingBei, SuiXi, } \\
\text { ZhanJiang, GuangDong, } \\
\text { China }\end{array}$ & $\begin{array}{l}\text { S.F. Chen, J.Q. Li \& } \\
\text { G.Q. Li }\end{array}$ & MF442684 & MF442799 & MF442914 & MF443014 \\
\hline & $\begin{array}{l}\text { CMW 47479; CERC } \\
7056\end{array}$ & AAAA & $\begin{array}{l}\text { E. urophylla } \times E \text {. grandis } \\
\text { seedling stem in nursery }\end{array}$ & $\begin{array}{l}\text { LingBei, SuiXi, } \\
\text { ZhanJiang, GuangDong, } \\
\text { China }\end{array}$ & $\begin{array}{l}\text { S.F. Chen, J.Q. Li \& } \\
\text { G.Q. Li }\end{array}$ & MF442685 & MF442800 & MF442915 & MF443015 \\
\hline & $\begin{array}{l}\text { CMW 47481; CERC } \\
7072\end{array}$ & AAAA & $\begin{array}{l}\text { E. urophylla } \times E \text {. grandis } \\
\text { seedling stem in nursery }\end{array}$ & $\begin{array}{l}\text { LingBei, SuiXi, } \\
\text { ZhanJiang, GuangDong, } \\
\text { China }\end{array}$ & $\begin{array}{l}\text { S.F. Chen, J.Q. Li \& } \\
\text { G.Q. Li }\end{array}$ & MF442686 & MF442801 & MF442916 & MF443016 \\
\hline & $\begin{array}{l}\text { CMW 474845; CERC } \\
7085\end{array}$ & AAAA & $\begin{array}{l}\text { E. urophylla } \times E \text {. grandis } \\
\text { seedling stem in nursery }\end{array}$ & $\begin{array}{l}\text { LingBei, SuiXi, } \\
\text { ZhanJiang, GuangDong, } \\
\text { China }\end{array}$ & $\begin{array}{l}\text { S.F. Chen, J.Q. Li \& } \\
\text { G.Q. Li }\end{array}$ & MF442687 & MF442802 & MF442917 & MF443017 \\
\hline \multirow[t]{5}{*}{ Ca. pentaseptata } & $\begin{array}{l}\text { CMW 47261; CERC } \\
3529\end{array}$ & AAAA & $\begin{array}{l}\text { E. urophylla } \times E \text {. grandis } \\
\text { seedling stem in nursery }\end{array}$ & $\begin{array}{l}\text { LingBei, SuiXi, } \\
\text { ZhanJiang, GuangDong, } \\
\text { China }\end{array}$ & S.F. Chen \& J.Q. Li & MF442688 & MF442803 & MF442918 & MF443018 \\
\hline & $\begin{array}{l}\text { CMW 47262; CERC } \\
3533\end{array}$ & AAAA & $\begin{array}{l}\text { E. urophylla } \times E \text {. grandis } \\
\text { seedling stem in nursery }\end{array}$ & $\begin{array}{l}\text { LingBei, SuiXi, } \\
\text { ZhanJiang, GuangDong, } \\
\text { China }\end{array}$ & S.F. Chen \& J.Q. Li & MF442689 & MF442804 & MF442919 & MF443019 \\
\hline & $\begin{array}{l}\text { CMW 47263; CERC } \\
3535\end{array}$ & AAAA & $\begin{array}{l}\text { E. urophylla } \times \text { E. grandis } \\
\text { seedling stem in nursery }\end{array}$ & $\begin{array}{l}\text { LingBei, SuiXi, } \\
\text { ZhanJiang, GuangDong, } \\
\text { China }\end{array}$ & S.F. Chen \& J.Q. Li & MF442690 & MF442805 & MF442920 & MF443020 \\
\hline & $\begin{array}{l}\text { CMW 47264; CERC } \\
3536\end{array}$ & AAAA & $\begin{array}{l}\text { E. urophylla } \times E \text {. grandis } \\
\text { seedling stem in nursery }\end{array}$ & $\begin{array}{l}\text { LingBei, SuiXi, } \\
\text { ZhanJiang, GuangDong, } \\
\text { China }\end{array}$ & S.F. Chen \& J.Q. Li & MF442691 & MF442806 & MF442921 & MF443021 \\
\hline & $\begin{array}{l}\text { CMW 47265; CERC } \\
3537\end{array}$ & AAAA & $\begin{array}{l}\text { E. urophylla } \times E \text {. grandis } \\
\text { seedling stem in nursery }\end{array}$ & $\begin{array}{l}\text { LingBei, SuiXi, } \\
\text { ZhanJiang, GuangDong, } \\
\text { China }\end{array}$ & S.F. Chen \& J.Q. Li & MF442692 & MF442807 & MF442922 & MF443022 \\
\hline
\end{tabular}


Table 1. (Continued).

\begin{tabular}{|c|c|c|c|c|c|c|c|c|c|}
\hline \multirow[t]{2}{*}{ Species $^{1}$} & \multirow[t]{2}{*}{ Isolate No. ${ }^{2}$} & \multirow[t]{2}{*}{ Haplotype $^{3}$} & \multirow[t]{2}{*}{ Substrate } & \multirow[t]{2}{*}{ Sampling site } & \multirow[t]{2}{*}{ Collector } & \multicolumn{4}{|c|}{ GenBank accession No. ${ }^{4}$} \\
\hline & & & & & & tef1 & his3 & $c m d A$ & tub2 \\
\hline & $\begin{array}{l}\text { CMW 47266; CERC } \\
3542\end{array}$ & AAAA & Soil in Eucalyptus nursery & $\begin{array}{l}\text { LingBei, SuiXi, } \\
\text { ZhanJiang, GuangDong, } \\
\text { China }\end{array}$ & S.F. Chen \& J.Q. Li & MF442693 & MF442808 & MF442923 & MF443023 \\
\hline & $\begin{array}{l}\text { CMW 47267; CERC } \\
3552\end{array}$ & AAAA & $\begin{array}{l}\text { E. urophylla } \times E \text {. grandis } \\
\text { seedling stem in nursery }\end{array}$ & $\begin{array}{l}\text { LingBei, SuiXi, } \\
\text { ZhanJiang, GuangDong, } \\
\text { China }\end{array}$ & S.F. Chen \& J.Q. Li & MF442694 & MF442809 & MF442924 & MF443024 \\
\hline & $\begin{array}{l}\text { CMW 47268; CERC } \\
3559\end{array}$ & AAAA & $\begin{array}{l}\text { E. urophylla } \times E \text {. grandis } \\
\text { seedling medium in nursery }\end{array}$ & $\begin{array}{l}\text { LingBei, SuiXi, } \\
\text { ZhanJiang, GuangDong, } \\
\text { China }\end{array}$ & S.F. Chen \& J.Q. Li & MF442695 & MF442810 & MF442925 & MF443025 \\
\hline & $\begin{array}{l}\text { CMW 47269; CERC } \\
3560\end{array}$ & AAAA & $\begin{array}{l}\text { E. urophylla } \times E \text {. grandis } \\
\text { seedling medium in nursery }\end{array}$ & $\begin{array}{l}\text { LingBei, SuiXi, } \\
\text { ZhanJiang, GuangDong, } \\
\text { China }\end{array}$ & S.F. Chen \& J.Q. Li & MF442696 & MF442811 & MF442926 & MF443026 \\
\hline & $\begin{array}{l}\text { CMW 472705; CERC } \\
3565\end{array}$ & AAAA & $\begin{array}{l}\text { E. urophylla } \times E \text {. grandis } \\
\text { seedling stem in nursery }\end{array}$ & $\begin{array}{l}\text { LingBei, SuiXi, } \\
\text { ZhanJiang, GuangDong, } \\
\text { China }\end{array}$ & S.F. Chen \& J.Q. Li & MF442697 & MF442812 & MF442927 & MF443027 \\
\hline & $\begin{array}{l}\text { CMW 472775; CERC } \\
3652\end{array}$ & AAAA & $\begin{array}{l}\text { E. urophylla } \times E \text {. grandis leaf } \\
\text { in plantation }\end{array}$ & $\begin{array}{l}\text { HengShan, LianJiang, } \\
\text { ZhanJiang, GuangDong, } \\
\text { China }\end{array}$ & $\begin{array}{l}\text { S.F. Chen, J.Q. Li \& } \\
\text { G.Q. Li }\end{array}$ & MF442698 & MF442813 & MF442928 & MF443028 \\
\hline & $\begin{array}{l}\text { CMW 47278; CERC } \\
3655\end{array}$ & AAAA & $\begin{array}{l}\text { E. urophylla } \times E \text {. grandis leaf } \\
\text { in plantation }\end{array}$ & $\begin{array}{l}\text { HengShan, LianJiang, } \\
\text { ZhanJiang, GuangDong, } \\
\text { China }\end{array}$ & $\begin{array}{l}\text { S.F. Chen, J.Q. Li \& } \\
\text { G.Q. Li }\end{array}$ & MF442699 & MF442814 & MF442929 & MF443029 \\
\hline & $\begin{array}{l}\text { CMW 47279; CERC } \\
3658\end{array}$ & AAAA & $\begin{array}{l}\text { E. urophylla } \times E \text {. grandis leaf } \\
\text { in plantation }\end{array}$ & $\begin{array}{l}\text { HengShan, LianJiang, } \\
\text { ZhanJiang, GuangDong, } \\
\text { China }\end{array}$ & $\begin{array}{l}\text { S.F. Chen, J.Q. Li \& } \\
\text { G.Q. Li }\end{array}$ & MF442700 & MF442815 & MF442930 & MF443030 \\
\hline & $\begin{array}{l}\text { CMW 47280; CERC } \\
3660\end{array}$ & AAAA & $\begin{array}{l}\text { E. urophylla } \times E \text {. grandis leaf } \\
\text { in plantation }\end{array}$ & $\begin{array}{l}\text { HengShan, LianJiang, } \\
\text { ZhanJiang, GuangDong, } \\
\text { China }\end{array}$ & $\begin{array}{l}\text { S.F. Chen, J.Q. Li \& } \\
\text { G.Q. Li }\end{array}$ & MF442701 & MF442816 & MF442931 & MF443031 \\
\hline & $\begin{array}{l}\text { CMW 47281; CERC } \\
3664\end{array}$ & AAAA & $\begin{array}{l}\text { E. urophylla } \times E \text {. grandis leaf } \\
\text { in plantation }\end{array}$ & $\begin{array}{l}\text { HengShan, LianJiang, } \\
\text { ZhanJiang, GuangDong, } \\
\text { China }\end{array}$ & $\begin{array}{l}\text { S.F. Chen, J.Q. Li \& } \\
\text { G.Q. Li }\end{array}$ & MF442702 & MF442817 & MF442932 & MF443032 \\
\hline & $\begin{array}{l}\text { CMW 47282; CERC } \\
3672\end{array}$ & AAAA & $\begin{array}{l}\text { E. urophylla } \times E \text {. grandis leaf } \\
\text { in plantation }\end{array}$ & $\begin{array}{l}\text { HengShan, LianJiang, } \\
\text { ZhanJiang, GuangDong, } \\
\text { China }\end{array}$ & $\begin{array}{l}\text { S.F. Chen, J.Q. Li \& } \\
\text { G.Q. Li }\end{array}$ & MF442703 & MF442818 & MF442933 & MF443033 \\
\hline & $\begin{array}{l}\text { CMW 47283; CERC } \\
3680\end{array}$ & AAAA & $\begin{array}{l}\text { E. urophylla } \times E \text {. grandis leaf } \\
\text { in plantation }\end{array}$ & $\begin{array}{l}\text { HengShan, LianJiang, } \\
\text { ZhanJiang, GuangDong, } \\
\text { China }\end{array}$ & $\begin{array}{l}\text { S.F. Chen, J.Q. Li \& } \\
\text { G.Q. Li }\end{array}$ & MF442704 & MF442819 & MF442934 & MF443034 \\
\hline & $\begin{array}{l}\text { CMW 47284; CERC } \\
3708\end{array}$ & AAAA & $\begin{array}{l}\text { E. urophylla } \times E \text {. grandis leaf } \\
\text { in plantation }\end{array}$ & $\begin{array}{l}\text { HengShan, LianJiang, } \\
\text { ZhanJiang, GuangDong, } \\
\text { China }\end{array}$ & $\begin{array}{l}\text { S.F. Chen, J.Q. Li \& } \\
\text { G.Q. Li }\end{array}$ & MF442705 & MF442820 & MF442935 & MF443035 \\
\hline
\end{tabular}




\begin{tabular}{|c|c|c|c|c|c|c|c|c|c|}
\hline \multirow[t]{2}{*}{ Species $^{1}$} & \multirow[t]{2}{*}{ Isolate No. ${ }^{2}$} & \multirow[t]{2}{*}{ Haplotype $^{3}$} & \multirow[t]{2}{*}{ Substrate } & \multirow[t]{2}{*}{ Sampling site } & \multirow[t]{2}{*}{ Collector } & \multicolumn{4}{|c|}{ GenBank accession No. ${ }^{4}$} \\
\hline & & & & & & tef1 & his3 & $c m d A$ & tub2 \\
\hline & $\begin{array}{l}\text { CMW 47285; CERC } \\
3720\end{array}$ & AAAA & $\begin{array}{l}\text { E. urophylla } \times E \text {. grandis leaf } \\
\text { in plantation }\end{array}$ & $\begin{array}{l}\text { HengShan, LianJiang, } \\
\text { ZhanJiang, GuangDong, } \\
\text { China }\end{array}$ & $\begin{array}{l}\text { S.F. Chen, J.Q. Li \& } \\
\text { G.Q. Li }\end{array}$ & MF442706 & MF442821 & MF442936 & MF443036 \\
\hline & $\begin{array}{l}\text { CMW 47463; CERC } \\
6963\end{array}$ & AAAA & $\begin{array}{l}\text { E. urophylla } \times \text { E. grandis } \\
\text { seedling leaf in nursery }\end{array}$ & $\begin{array}{l}\text { LingBei, SuiXi, } \\
\text { ZhanJiang, GuangDong, } \\
\text { China }\end{array}$ & S.F. Chen \& G.Q. Li & MF442707 & MF442822 & MF442937 & MF443037 \\
\hline & $\begin{array}{l}\text { CMW 47464; CERC } \\
6973\end{array}$ & AAAA & $\begin{array}{l}\text { E. urophylla } \times \text { E. grandis } \\
\text { seedling leaf in nursery }\end{array}$ & $\begin{array}{l}\text { LingBei, SuiXi, } \\
\text { ZhanJiang, GuangDong, } \\
\text { China }\end{array}$ & S.F. Chen \& G.Q. Li & MF442708 & MF442823 & MF442938 & MF443038 \\
\hline & $\begin{array}{l}\text { CMW 47468; CERC } \\
6999\end{array}$ & AAAA & $\begin{array}{l}\text { E. urophylla } \times \text { E. grandis } \\
\text { seedling stem in nursery }\end{array}$ & $\begin{array}{l}\text { LingBei, SuiXi, } \\
\text { ZhanJiang, GuangDong, } \\
\text { China }\end{array}$ & $\begin{array}{l}\text { S.F. Chen, J.Q. Li \& } \\
\text { G.Q. Li }\end{array}$ & MF442709 & MF442824 & MF442939 & MF443039 \\
\hline & $\begin{array}{l}\text { CMW 47470; CERC } \\
7012\end{array}$ & AAAA & $\begin{array}{l}\text { E. urophylla } \times \text { E. grandis } \\
\text { seedling stem in nursery }\end{array}$ & $\begin{array}{l}\text { LingBei, SuiXi, } \\
\text { ZhanJiang, GuangDong, } \\
\text { China }\end{array}$ & $\begin{array}{l}\text { S.F. Chen, J.Q. Li \& } \\
\text { G.Q. Li }\end{array}$ & MF442710 & MF442825 & MF442940 & MF443040 \\
\hline & $\begin{array}{l}\text { CMW 47471; CERC } \\
7018\end{array}$ & AAAA & $\begin{array}{l}\text { E. urophylla } \times \text { E. grandis } \\
\text { seedling stem in nursery }\end{array}$ & $\begin{array}{l}\text { LingBei, SuiXi, } \\
\text { ZhanJiang, GuangDong, } \\
\text { China }\end{array}$ & $\begin{array}{l}\text { S.F. Chen, J.Q. Li \& } \\
\text { G.Q. Li }\end{array}$ & MF442711 & MF442826 & MF442941 & MF443041 \\
\hline & $\begin{array}{l}\text { CMW 47473; CERC } \\
7024\end{array}$ & AAAA & $\begin{array}{l}\text { E. urophylla } \times \text { E. grandis } \\
\text { seedling stem in nursery }\end{array}$ & $\begin{array}{l}\text { LingBei, SuiXi, } \\
\text { ZhanJiang, GuangDong, } \\
\text { China }\end{array}$ & $\begin{array}{l}\text { S.F. Chen, J.Q. Li \& } \\
\text { G.Q. Li }\end{array}$ & MF442712 & MF442827 & MF442942 & MF443042 \\
\hline & $\begin{array}{l}\text { CMW 47474; CERC } \\
7030\end{array}$ & AAAA & $\begin{array}{l}\text { E. urophylla } \times \text { E. grandis } \\
\text { seedling stem in nursery }\end{array}$ & $\begin{array}{l}\text { LingBei, SuiXi, } \\
\text { ZhanJiang, GuangDong, } \\
\text { China }\end{array}$ & $\begin{array}{l}\text { S.F. Chen, J.Q. Li \& } \\
\text { G.Q. Li }\end{array}$ & MF442713 & MF442828 & MF442943 & MF443043 \\
\hline & $\begin{array}{l}\text { CMW 47475; CERC } \\
7036\end{array}$ & AAAA & $\begin{array}{l}\text { E. urophylla } \times \text { E. grandis } \\
\text { seedling stem in nursery }\end{array}$ & $\begin{array}{l}\text { LingBei, SuiXi, } \\
\text { ZhanJiang, GuangDong, } \\
\text { China }\end{array}$ & $\begin{array}{l}\text { S.F. Chen, J.Q. Li \& } \\
\text { G.Q. Li }\end{array}$ & MF442714 & MF442829 & MF442944 & MF443044 \\
\hline & $\begin{array}{l}\text { CMW 47477; CERC } \\
7047\end{array}$ & AAAA & $\begin{array}{l}\text { E. urophylla } \times \text { E. grandis } \\
\text { seedling stem in nursery }\end{array}$ & $\begin{array}{l}\text { LingBei, SuiXi, } \\
\text { ZhanJiang, GuangDong, } \\
\text { China }\end{array}$ & $\begin{array}{l}\text { S.F. Chen, J.Q. Li \& } \\
\text { G.Q. Li }\end{array}$ & MF442715 & MF442830 & MF442945 & MF443045 \\
\hline & $\begin{array}{l}\text { CMW 47480; CERC } \\
7060\end{array}$ & AAAA & $\begin{array}{l}\text { E. urophylla } \times E \text {. grandis } \\
\text { seedling stem in nursery }\end{array}$ & $\begin{array}{l}\text { LingBei, SuiXi, } \\
\text { ZhanJiang, GuangDong, } \\
\text { China }\end{array}$ & $\begin{array}{l}\text { S.F. Chen, J.Q. Li \& } \\
\text { G.Q. Li }\end{array}$ & MF442716 & MF442831 & MF442946 & MF443046 \\
\hline & $\begin{array}{l}\text { CMW 47482; CERC } \\
7074\end{array}$ & AAAA & $\begin{array}{l}\text { E. urophylla } \times E \text {. grandis } \\
\text { seedling stem in nursery }\end{array}$ & $\begin{array}{l}\text { LingBei, SuiXi, } \\
\text { ZhanJiang, GuangDong, } \\
\text { China }\end{array}$ & $\begin{array}{l}\text { S.F. Chen, J.Q. Li \& } \\
\text { G.Q. Li }\end{array}$ & MF442717 & MF442832 & MF442947 & MF443047 \\
\hline & $\begin{array}{l}\text { CMW 47483; CERC } \\
7081\end{array}$ & AAAA & $\begin{array}{l}\text { E. urophylla } \times \text { E. grandis } \\
\text { seedling stem in nursery }\end{array}$ & $\begin{array}{l}\text { LingBei, SuiXi, } \\
\text { ZhanJiang, GuangDong, } \\
\text { China }\end{array}$ & $\begin{array}{l}\text { S.F. Chen, J.Q. Li \& } \\
\text { G.Q. Li }\end{array}$ & MF442718 & MF442833 & MF442948 & MF443048 \\
\hline
\end{tabular}


Table 1. (Continued).

\begin{tabular}{|c|c|c|c|c|c|c|c|c|c|}
\hline \multirow[t]{2}{*}{ Species $^{1}$} & \multirow[t]{2}{*}{ Isolate No. ${ }^{2}$} & \multirow[t]{2}{*}{ Haplotype $^{3}$} & \multirow[t]{2}{*}{ Substrate } & \multirow[t]{2}{*}{ Sampling site } & \multirow[t]{2}{*}{ Collector } & \multicolumn{4}{|c|}{ GenBank accession No. ${ }^{4}$} \\
\hline & & & & & & tef1 & his3 & $c m d A$ & tub2 \\
\hline & $\begin{array}{l}\text { CMW 47485; CERC } \\
7087\end{array}$ & AAAA & $\begin{array}{l}\text { E. urophylla } \times \text { E. grandis } \\
\text { seedling stem in nursery }\end{array}$ & $\begin{array}{l}\text { LingBei, SuiXi, } \\
\text { ZhanJiang, GuangDong, } \\
\text { China }\end{array}$ & $\begin{array}{l}\text { S.F. Chen, J.Q. Li \& } \\
\text { G.Q. Li }\end{array}$ & MF442719 & MF442834 & MF442949 & MF443049 \\
\hline & $\begin{array}{l}\text { CMW 47486; CERC } \\
7095\end{array}$ & AAAA & $\begin{array}{l}\text { E. urophylla } \times \text { E. grandis } \\
\text { seedling stem in nursery }\end{array}$ & $\begin{array}{l}\text { LingBei, SuiXi, } \\
\text { ZhanJiang, GuangDong, } \\
\text { China }\end{array}$ & $\begin{array}{l}\text { S.F. Chen, J.Q. Li \& } \\
\text { G.Q. Li }\end{array}$ & MF442720 & MF442835 & MF442950 & MF443050 \\
\hline & $\begin{array}{l}\text { CMW 47487; CERC } \\
7104\end{array}$ & AAAA & $\begin{array}{l}\text { E. urophylla } \times \text { E. grandis } \\
\text { seedling stem in nursery }\end{array}$ & $\begin{array}{l}\text { LingBei, SuiXi, } \\
\text { ZhanJiang, GuangDong, } \\
\text { China }\end{array}$ & $\begin{array}{l}\text { S.F. Chen, J.Q. Li \& } \\
\text { G.Q. Li }\end{array}$ & MF442721 & MF442836 & MF442951 & MF443051 \\
\hline & $\begin{array}{l}\text { CMW 475105; CERC } \\
9529\end{array}$ & AAAA & $\begin{array}{l}\text { Eucalyptus clone seedling } \\
\text { stem in nursery }\end{array}$ & $\begin{array}{l}\text { CERC, XiaShan, } \\
\text { ZhanJiang, GuangDong, } \\
\text { China }\end{array}$ & J.Q. Li \& S.F. Chen & MF442722 & MF442837 & MF442952 & MF443052 \\
\hline & $\begin{array}{l}\text { CMW 47511; CERC } \\
9533\end{array}$ & AAAA & $\begin{array}{l}\text { Eucalyptus clone seedling } \\
\text { stem in nursery }\end{array}$ & $\begin{array}{l}\text { CERC, XiaShan, } \\
\text { ZhanJiang, GuangDong, } \\
\text { China }\end{array}$ & J.Q. Li \& S.F. Chen & MF442723 & MF442838 & MF442953 & MF443053 \\
\hline & $\begin{array}{l}\text { CMW 47512; CERC } \\
9541\end{array}$ & AAAA & $\begin{array}{l}\text { Eucalyptus clone seedling } \\
\text { stem in nursery }\end{array}$ & $\begin{array}{l}\text { CERC, XiaShan, } \\
\text { ZhanJiang, GuangDong, } \\
\text { China }\end{array}$ & J.Q. Li \& S.F. Chen & MF442724 & MF442839 & MF442954 & MF443054 \\
\hline & $\begin{array}{l}\text { CMW 47513; CERC } \\
9556\end{array}$ & AAAA & $\begin{array}{l}\text { Eucalyptus clone seedling } \\
\text { leaf in nursery }\end{array}$ & $\begin{array}{l}\text { CERC, XiaShan, } \\
\text { ZhanJiang, GuangDong, } \\
\text { China }\end{array}$ & J.Q. Li \& S.F. Chen & MF442725 & MF442840 & MF442955 & MF443055 \\
\hline & $\begin{array}{l}\text { CMW 47514; CERC } \\
9565\end{array}$ & AAAA & $\begin{array}{l}\text { Eucalyptus clone seedling } \\
\text { stem in nursery }\end{array}$ & $\begin{array}{l}\text { CERC, XiaShan, } \\
\text { ZhanJiang, GuangDong, } \\
\text { China }\end{array}$ & J.Q. Li \& S.F. Chen & MF442726 & MF442841 & MF442956 & MF443056 \\
\hline & $\begin{array}{l}\text { CMW 47515; CERC } \\
9572\end{array}$ & AAAA & $\begin{array}{l}\text { Eucalyptus clone seedling } \\
\text { stem in nursery }\end{array}$ & $\begin{array}{l}\text { CERC, XiaShan, } \\
\text { ZhanJiang, GuangDong, } \\
\text { China }\end{array}$ & J.Q. Li \& S.F. Chen & MF442727 & MF442842 & MF442957 & MF443057 \\
\hline & $\begin{array}{l}\text { CMW 47620; CERC } \\
3722\end{array}$ & AAAA & $\begin{array}{l}\text { E. urophylla } \times E \text {. grandis leaf } \\
\text { in plantation }\end{array}$ & $\begin{array}{l}\text { HengShan, LianJiang, } \\
\text { ZhanJiang, GuangDong, } \\
\text { China }\end{array}$ & $\begin{array}{l}\text { S.F. Chen, J.Q. Li \& } \\
\text { G.Q. Li }\end{array}$ & MF442728 & MF442843 & MF442958 & MF443058 \\
\hline & $\begin{array}{l}\text { CMW 47621; CERC } \\
3730\end{array}$ & AAAA & $\begin{array}{l}\text { E. urophylla } \times \text { E. grandis } \\
\text { stem in plantation }\end{array}$ & $\begin{array}{l}\text { HengShan, LianJiang, } \\
\text { ZhanJiang, GuangDong, } \\
\text { China }\end{array}$ & $\begin{array}{l}\text { S.F. Chen, J.Q. Li \& } \\
\text { G.Q. Li }\end{array}$ & MF442729 & MF442844 & MF442959 & MF443059 \\
\hline & $\begin{array}{l}\text { CMW 47622; CERC } \\
3736\end{array}$ & AAAA & $\begin{array}{l}\text { E. urophylla } \times E \text {. grandis leaf } \\
\text { in plantation }\end{array}$ & $\begin{array}{l}\text { HengShan, LianJiang, } \\
\text { ZhanJiang, GuangDong, } \\
\text { China }\end{array}$ & $\begin{array}{l}\text { S.F. Chen, J.Q. Li \& } \\
\text { G.Q. Li }\end{array}$ & MF442730 & MF442845 & MF442960 & MF443060 \\
\hline & $\begin{array}{l}\text { CMW 47623; CERC } \\
3742\end{array}$ & AAAA & $\begin{array}{l}\text { E. urophylla } \times E \text {. grandis leaf } \\
\text { in plantation }\end{array}$ & $\begin{array}{l}\text { HengShan, LianJiang, } \\
\text { ZhanJiang, GuangDong, } \\
\text { China }\end{array}$ & $\begin{array}{l}\text { S.F. Chen, J.Q. Li \& } \\
\text { G.Q. Li }\end{array}$ & MF442731 & MF442846 & MF442961 & MF443061 \\
\hline
\end{tabular}




\begin{tabular}{|c|c|c|c|c|c|c|c|c|c|}
\hline \multirow[t]{2}{*}{ Species $^{1}$} & \multirow[t]{2}{*}{ Isolate No. ${ }^{2}$} & \multirow[t]{2}{*}{ Haplotype $^{3}$} & \multirow[t]{2}{*}{ Substrate } & \multirow[t]{2}{*}{ Sampling site } & \multirow[t]{2}{*}{ Collector } & \multicolumn{4}{|c|}{ GenBank accession No. ${ }^{4}$} \\
\hline & & & & & & tef1 & his3 & $c m d A$ & tub2 \\
\hline & $\begin{array}{l}\text { CMW 47624; CERC } \\
3752\end{array}$ & AAAA & $\begin{array}{l}\text { E. urophylla } \times E \text {. grandis leaf } \\
\text { in plantation }\end{array}$ & $\begin{array}{l}\text { HengShan, LianJiang, } \\
\text { ZhanJiang, GuangDong, } \\
\text { China }\end{array}$ & $\begin{array}{l}\text { S.F. Chen, J.Q. Li \& } \\
\text { G.Q. Li }\end{array}$ & MF442732 & MF442847 & MF442962 & MF443062 \\
\hline & $\begin{array}{l}\text { CMW 47625; CERC } \\
3758\end{array}$ & AAAA & $\begin{array}{l}\text { E. urophylla } \times E \text {. grandis leaf } \\
\text { in plantation }\end{array}$ & $\begin{array}{l}\text { HengShan, LianJiang, } \\
\text { ZhanJiang, GuangDong, } \\
\text { China }\end{array}$ & $\begin{array}{l}\text { S.F. Chen, J.Q. Li \& } \\
\text { G.Q. Li }\end{array}$ & MF442733 & MF442848 & MF442963 & MF443063 \\
\hline & $\begin{array}{l}\text { CMW 47626; CERC } \\
4987\end{array}$ & AAAA & $\begin{array}{l}\text { E. urophylla } \times E \text {. grandis leaf } \\
\text { in plantation }\end{array}$ & $\begin{array}{l}\text { JiuHe, ZiJin, HeYuan, } \\
\text { GuangDong, China }\end{array}$ & S.F. Chen \& J.Q. Li & MF442734 & MF442849 & MF442964 & MF443064 \\
\hline & $\begin{array}{l}\text { CMW 47627; CERC } \\
4989\end{array}$ & AAAA & $\begin{array}{l}\text { E. urophylla } \times E \text {. grandis leaf } \\
\text { in plantation }\end{array}$ & $\begin{array}{l}\text { JiuHe, ZiJin, HeYuan, } \\
\text { GuangDong, China }\end{array}$ & S.F. Chen \& J.Q. Li & MF442735 & MF442850 & MF442965 & MF443065 \\
\hline & $\begin{array}{l}\text { CMW } 47628^{5} ; \text { CERC } \\
4992\end{array}$ & AAAA & $\begin{array}{l}\text { E. urophylla } \times E \text {. grandis leaf } \\
\text { in plantation }\end{array}$ & $\begin{array}{l}\text { JiuHe, ZiJin, HeYuan, } \\
\text { GuangDong, China }\end{array}$ & S.F. Chen \& J.Q. Li & MF442736 & MF442851 & MF442966 & MF443066 \\
\hline & $\begin{array}{l}\text { CMW 47629; CERC } \\
4994\end{array}$ & AAAA & $\begin{array}{l}\text { E. urophylla } \times E \text {. grandis leaf } \\
\text { in plantation }\end{array}$ & $\begin{array}{l}\text { JiuHe, ZiJin, HeYuan, } \\
\text { GuangDong, China }\end{array}$ & S.F. Chen \& J.Q. Li & MF442737 & MF442852 & MF442967 & MF443067 \\
\hline & $\begin{array}{l}\text { CMW 47630; CERC } \\
5005\end{array}$ & AAAA & $\begin{array}{l}\text { E. urophylla } \times E \text {. grandis leaf } \\
\text { in plantation }\end{array}$ & $\begin{array}{l}\text { TongHe, PingNan, } \\
\text { GuiGang, GuangXi, } \\
\text { China }\end{array}$ & S.F. Chen \& J.Q. Li & MF442738 & MF442853 & MF442968 & MF443068 \\
\hline & $\begin{array}{l}\text { CMW 476315; CERC } \\
5009\end{array}$ & AAAA & $\begin{array}{l}\text { E. urophylla } \times E \text {. grandis leaf } \\
\text { in plantation }\end{array}$ & $\begin{array}{l}\text { TongHe, PingNan, } \\
\text { GuiGang, GuangXi, } \\
\text { China }\end{array}$ & S.F. Chen \& J.Q. Li & MF442739 & MF442854 & MF442969 & MF443069 \\
\hline & $\begin{array}{l}\text { CMW 47632; CERC } \\
5022\end{array}$ & AAAA & $\begin{array}{l}\text { E. urophylla } \times E \text {. grandis leaf } \\
\text { in plantation }\end{array}$ & $\begin{array}{l}\text { TongHe, PingNan, } \\
\text { GuiGang, GuangXi, } \\
\text { China }\end{array}$ & S.F. Chen \& J.Q. Li & MF442740 & MF442855 & MF442970 & MF443070 \\
\hline & $\begin{array}{l}\text { CMW 47633; CERC } \\
5307\end{array}$ & AAAA & $\begin{array}{l}\text { E. urophylla } \times E \text {. grandis leaf } \\
\text { in plantation }\end{array}$ & $\begin{array}{l}\text { ChengYue, SuiXi, } \\
\text { ZhanJiang GuangDong, } \\
\text { China }\end{array}$ & S.F. Chen \& J.Q. Li & MF442741 & MF442856 & MF442971 & MF443071 \\
\hline & $\begin{array}{l}\text { CMW 47634; CERC } \\
5310\end{array}$ & AAAA & $\begin{array}{l}\text { E. urophylla } \times E \text {. grandis leaf } \\
\text { in plantation }\end{array}$ & $\begin{array}{l}\text { ChengYue, SuiXi, } \\
\text { ZhanJiang GuangDong, } \\
\text { China }\end{array}$ & S.F. Chen \& J.Q. Li & MF442742 & MF442857 & MF442972 & MF443072 \\
\hline & $\begin{array}{l}\text { CMW 476355; CERC } \\
5313\end{array}$ & AAAA & $\begin{array}{l}\text { E. urophylla } \times E \text {. grandis leaf } \\
\text { in plantation }\end{array}$ & $\begin{array}{l}\text { ChengYue, SuiXi, } \\
\text { ZhanJiang GuangDong, } \\
\text { China }\end{array}$ & S.F. Chen \& J.Q. Li & MF442743 & MF442858 & MF442973 & MF443073 \\
\hline & $\begin{array}{l}\text { CMW 47636; CERC } \\
5317\end{array}$ & AAAA & $\begin{array}{l}\text { E. urophylla } \times E \text {. grandis leaf } \\
\text { in plantation }\end{array}$ & $\begin{array}{l}\text { ChengYue, SuiXi, } \\
\text { ZhanJiang GuangDong, } \\
\text { China }\end{array}$ & S.F. Chen \& J.Q. Li & MF442744 & MF442859 & MF442974 & MF443074 \\
\hline Ca. pseudoturangicola & $\begin{array}{l}\text { CMW } 47247^{5} ; \text { CERC } \\
3250\end{array}$ & AAAA & Soil & $\begin{array}{l}\text { Lantau, Lidao, Hong } \\
\text { Kong, China }\end{array}$ & $\begin{array}{l}\text { M.J. Wingfield \& } \\
\text { S.F. Chen }\end{array}$ & MF442745 & MF442860 & MF442975 & MF443075 \\
\hline & $\begin{array}{l}\text { CMW 472485; CERC } \\
3251\end{array}$ & AAAA & Soil & $\begin{array}{l}\text { Lantau, Lidao, Hong } \\
\text { Kong, China }\end{array}$ & $\begin{array}{l}\text { M.J. Wingfield \& } \\
\text { S.F. Chen }\end{array}$ & MF442746 & MF442861 & MF442976 & MF443076 \\
\hline
\end{tabular}


Table 1. (Continued).

\begin{tabular}{|c|c|c|c|c|c|c|c|c|c|}
\hline \multirow[t]{2}{*}{ Species $^{1}$} & \multirow[t]{2}{*}{ Isolate No. $^{2}$} & \multirow[t]{2}{*}{ Haplotype $^{3}$} & \multirow[t]{2}{*}{ Substrate } & \multirow[t]{2}{*}{ Sampling site } & \multirow[t]{2}{*}{ Collector } & \multicolumn{4}{|c|}{ GenBank accession No. ${ }^{4}$} \\
\hline & & & & & & tef1 & his3 & $c m d A$ & tub2 \\
\hline & $\begin{array}{l}\text { CMW 474885; CERC } \\
7111\end{array}$ & AAAA & Soil in Eucalyptus plantation & $\begin{array}{l}\text { BaiSha, MinHou, } \\
\text { FuZhou, FuJian, China }\end{array}$ & S.F. Chen & MF442747 & MF442862 & MF442977 & MF443077 \\
\hline & $\begin{array}{l}\text { CMW 474895-7; CERC } \\
7115 ; \text { CBS } 142889\end{array}$ & AAAA & Soil in Eucalyptus plantation & $\begin{array}{l}\text { BaiSha, MinHou, } \\
\text { FuZhou, FuJian, China }\end{array}$ & S.F. Chen & MF442748 & MF442863 & MF442978 & MF443078 \\
\hline & $\begin{array}{l}\text { CMW } 47490^{5} ; \text { CERC } \\
7116\end{array}$ & AAAA & Soil in Eucalyptus plantation & $\begin{array}{l}\text { BaiSha, MinHou, } \\
\text { FuZhou, FuJian, China }\end{array}$ & S.F. Chen & MF442749 & MF442864 & MF442979 & MF443079 \\
\hline & $\begin{array}{l}\text { CMW 474965-8; CERC } \\
\text { 7126; CBS } 142890\end{array}$ & AAAA & Soil & $\begin{array}{l}\text { FAFU, CangShan, } \\
\text { FuZhou, FuJian, China }\end{array}$ & S.F. Chen & MF442750 & MF442865 & MF442980 & MF443080 \\
\hline & $\begin{array}{l}\text { CMW 474975-7; CERC } \\
\text { 7127; CBS } 142891\end{array}$ & AAAB & Soil & $\begin{array}{l}\text { FAFU, CangShan, } \\
\text { FuZhou, FuJian, China }\end{array}$ & S.F. Chen & MF442751 & MF442866 & MF442981 & MF443081 \\
\hline & $\begin{array}{l}\text { CMW 474985; CERC } \\
7131\end{array}$ & AAAB & Soil & $\begin{array}{l}\text { FAFU, CangShan, } \\
\text { FuZhou, FuJian, China }\end{array}$ & S.F. Chen & MF442752 & MF442867 & MF442982 & MF443082 \\
\hline \multirow[t]{3}{*}{$\begin{array}{l}\text { Ca. } \\
\text { pseudoyunnanensis }\end{array}$} & $\begin{array}{l}\text { CMW 47655 5-8; CERC } \\
\text { 5376; CBS } 142892\end{array}$ & AAAA & Soil in Eucalyptus plantation & $\begin{array}{l}\text { WeiYuan, JingGu, PuEr, } \\
\text { YunNan, China }\end{array}$ & $\begin{array}{l}\text { S.F. Chen, J.Q. Li \& } \\
\text { G.Q. Li }\end{array}$ & MF442753 & MF442868 & MF442983 & MF443083 \\
\hline & $\begin{array}{l}\text { CMW 47656 5-7; CERC } \\
5377 \text {; CBS } 142893\end{array}$ & AAAA & Soil in Eucalyptus plantation & $\begin{array}{l}\text { WeiYuan, JingGu, PuEr, } \\
\text { YunNan, China }\end{array}$ & $\begin{array}{l}\text { S.F. Chen, J.Q. Li \& } \\
\text { G.Q. Li }\end{array}$ & MF442754 & MF442869 & MF442984 & MF443084 \\
\hline & $\begin{array}{l}\text { CMW 476575-7; CERC } \\
\text { 5378; CBS } 142894\end{array}$ & AAAA & Soil in Eucalyptus plantation & $\begin{array}{l}\text { WeiYuan, JingGu, PuEr, } \\
\text { YunNan, China }\end{array}$ & $\begin{array}{l}\text { S.F. Chen, J.Q. Li \& } \\
\text { G.Q. Li }\end{array}$ & MF442755 & MF442870 & MF442985 & MF443085 \\
\hline \multirow[t]{3}{*}{ Ca. yunnanensis } & $\begin{array}{l}\text { CMW 47642 }{ }^{5-7} \text {; CERC } \\
\text { 5337; CBS } 142895\end{array}$ & AAAA & Soil in Eucalyptus plantation & $\begin{array}{l}\text { ZhengXing, JingGu, } \\
\text { PuEr, YunNan, China }\end{array}$ & $\begin{array}{l}\text { S.F. Chen, J.Q. Li \& } \\
\text { G.Q. Li }\end{array}$ & MF442756 & MF442871 & MF442986 & MF443086 \\
\hline & $\begin{array}{l}\text { CMW 476435-7; CERC } \\
\text { 5338; CBS } 142896\end{array}$ & AAAA & Soil in Eucalyptus plantation & $\begin{array}{l}\text { ZhengXing, JingGu, } \\
\text { PuEr, YunNan, China }\end{array}$ & $\begin{array}{l}\text { S.F. Chen, J.Q. Li \& } \\
\text { G.Q. Li }\end{array}$ & MF442757 & MF442872 & MF442987 & MF443087 \\
\hline & $\begin{array}{l}\text { CMW 476445-8; CERC } \\
\text { 5339; CBS } 142897\end{array}$ & AAAA & Soil in Eucalyptus plantation & $\begin{array}{l}\text { ZhengXing, JingGu, } \\
\text { PuEr, YunNan, China }\end{array}$ & $\begin{array}{l}\text { S.F. Chen, J.Q. Li \& } \\
\text { G.Q. Li }\end{array}$ & MF442758 & MF442873 & MF442988 & MF443088 \\
\hline
\end{tabular}

${ }^{1}$ New species described in this study are indicated in bold.

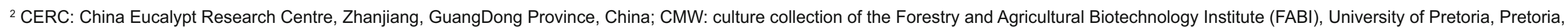
South Africa. CBS: culture collection of Westerdijk Fungal Biodiversity Institute, Utrecht, The Netherlands.

${ }^{3}$ Haplotype within each identified species, determined by sequences of tef1, his $3, c m d A$ and tub2 regions.

${ }^{4}$ tef1 $=$ translation elongation factor 1 -alpha; his3 = histone $\mathrm{H} 3 ; \mathrm{cmdA}=$ calmodulin; tub2 $=\beta$-tubulin.

${ }^{5}$ Isolates used in phylogenetic analyses.

${ }^{6}$ Isolates used in morphological studies.

${ }^{7}$ Isolates used in growth studies.

${ }^{8}$ Isolates that represent ex-type cultures are indicated in bold

9 "-" represents sequences that are not available. 
sequences from ex-type strains of Calonectria downloaded from NCBI (http://www.ncbi.nlm.nih.gov) and subjected to phylogenetic analyses. Sequences generated in this study and those from $\mathrm{NCBI}$ were aligned using the online version of MAFFT v. 7 (http://mafft.cbrc.jp/alignment/server; Katho \& Standley 2013) with the interactive refinement method (FFT-NS-i) setting. The aligned sequences were edited manually in MEGA v. 6 (Tamura et al. 2013) where necessary and deposited in TreeBASE (http://treebase.org). Single nucleotide polymorphisms (SNPs) were determined for each gene region between novel species identified in this study and their phylogenetically closest related species.

Based on sequences for $\mathrm{cmdA}$, his3, tef1 and tub2 gene regions, the haplotypes of obtained Calonectria isolates were determined. Isolates representing different haplotypes and representing all the sampling sites were selected for the phylogenetic analyses. For the new species identified here, all the isolates were included in the analyses. The datasets were separated into two groups based on morphological characteristics representing the Prolate Group and the Sphaero-Naviculate Group, as defined by Lombard et al. (2010c). Phylogenetic analyses were conducted separately on the datasets for each of the four gene regions and combined data for three or four gene regions for the two groups, depending on the availability of tub2 sequences for the Calonectria species selected for the phylogenetic analyses. A partition homogeneity test (PHT) was used to test whether conflict existed between the different datasets, the sequence data for coding gene regions were combined if no significant conflict (Cunningham 1997, Dettman et al. 2003). Data were analysed using Maximum Parsimony (MP) with

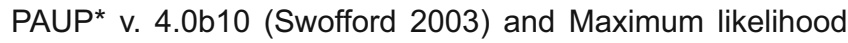
(ML) with PhyML v. 3.0 (Guindon \& Gascuel 2003).

For MP analyses, gaps were treated as a fifth character (Ogden \& Rosenberg 2007) and the characters were unordered and of equal weight with 1000 random addition replicates. The most parsimonious trees were generated using the heuristic search option with random stepwise addition of 1000 replicates and tree bisection and reconstruction (TBR) branch swapping. Zero-length branches were collapsed. Statistical support for internal nodes in trees was set with 1000 bootstrap replicates. Statistics estimated for parsimony included tree length ( $T L)$, retention index $(R I)$, consistency index $(\mathrm{Cl})$, rescaled consistency indexes $(\mathrm{RC})$ and homoplasy index (HI) (Hillis \& Bull 1993).

For $\mathrm{ML}$ analyses, the appropriate models were obtained with jModeltest v. 2.1.5 (Posada 2008). The maximum number of retained trees was set to 1000 and the confidence levels for node support were determined using nonparametric bootstrapping with 1000 replicates. Calonectria hongkongensis (CBS 114828 and CBS 114711) and Ca. pauciramosa (CMW 5683 and CMW 30823) were used as the outgroup taxa for the Prolate Group and Sphaero-Naviculate Group, respectively. For all the analyses, the phylogenetic trees were viewed using MEGA v. 6 (Tamura et al. 2013).

\section{Morphology}

Isolates were examined to define the characteristics of the asexual sporing structures. Single hyphal tip isolates were transferred to synthetic nutrient-poor agar (SNA; Nirenberg
1981, Lombard et al. 2010b, c) and incubated at room temperature for 7-15 d. The structures were examined and recorded using a Zeiss Axio Imager A1 microscope and a Zeiss AxioCam MRc digital camera with Zeiss Axio Vision Rel. 4.8 software (Carl Zeiss, Munchen). Morphological characteristics were studied by mounting the structures in a drop of $85 \%$ lactic acid on glass slides. For the known Calonectria species, the structures were compared with those published of the type specimens. For those species shown to represent novel phylogenetic species, for ascospores, asci, conidia, and vesicles, 50 measurements were made for the isolates selected to represent the holotype specimen. In addition, 30 measurements were made for paratype specimens. Minimum, maximum and average (mean) values were calculated and are presented as (minimum-) (average - standard deviation)-(average + standard deviation) (maximum). For all other taxonomic informative structures, only the extremes are given.

The optimal growth conditions for cultures representing novel species were determined on MEA in the dark at temperatures ranging from $5-35^{\circ} \mathrm{C}$ with $5{ }^{\circ} \mathrm{C}$ intervals. Four replicates were used for each isolate at each temperature. Two diameter measurements, perpendicular to each other, were measured daily for $7 \mathrm{~d}$. Colony morphology and colour were determined on MEA after growth at $25^{\circ} \mathrm{C}$ in the dark for $7 \mathrm{~d}$ using the colour charts of Rayner (1970). All descriptions were deposited in MycoBank (www.mycobank.org; Crous et al. 2004).

\section{Sexual compatibility}

Isolates of each novel Calonectria species identified based on multi-gene phylogenetic analyses were crossed with each other in all possible combinations. Crosses were made on minimal salt agar (MSA) on which sterile toothpicks had been placed on the surface of the media (Geurber \& Correll 2001, Lombard et al. 2010b, c) and incubated at room temperature. Isolates crossed with themselves served as controls, and it was thus possible to distinguish between those species with heterothallic or homothallic mating systems. Crosses were regarded as successful when isolate combinations produced perithecia extruding viable ascospores.

After 4-6 wk of incubation, the perithecia obtained from the sexual compatibility tests were mounted in Leica Biosystems Tissue Freezing Medium (Leica Biosystems Nussloch, Nussloch, Germany) and sectioned using a Microtome Cryostat Microm HM550 (Microm International, Thermo Fisher Scientific, Walldorf, Germany) at $-20{ }^{\circ} \mathrm{C}$ to observe characteristics of the ascomata and ascostromatic tissues. The $12 \mu \mathrm{m}$ sections were mounted in $85 \%$ lactic acid and $3 \% \mathrm{KOH}$, and all taxonomically informative structures were measured in the same manner as that for the asexual structures.

\section{RESULTS}

\section{Isolates}

A total of 115 isolates having morphological characteristics typical of Calonectria spp. were obtained. Of these, 64 isolates were from GuangDong Province, 16 from GuangXi 
Province, 15 from YunNan Province, 10 from FuJian Province, and 10 isolates were from soil in a natural forested area in the Hong Kong Region. All of these isolates were either from soil samples (mostly from beneath Eucalyptus trees), from infected leaves on Eucalyptus trees or from Eucalyptus plants in nurseries (Table 1).

\section{Phylogenetic analyses}

All 115 isolates obtained in this study were sequenced (Table 1). Thus, approximately $475 \mathrm{bp}$ were generated for the $\mathrm{cmdA}$ gene region, $435 \mathrm{bp}$ for the his 3 gene region, $500 \mathrm{bp}$ for the tef1 gene region and $565 \mathrm{bp}$ for the tub2 gene region. The 115 isolates represent 16 haplotypes determined by sequences for the four gene regions (Table 1). In total, 40 isolates collected in this study which represent all the 16 haplotypes were selected for phylogenetic analyses. Based on the comparsions for four gene region sequences generated in this study and published sequences from ex-type strains of Calonectria downloaded from $\mathrm{NCBI}$, sequences for 65 ex-type and other strains representing 34 species closely related to specie emerging from this study were used for analyses (Supplementary Table 2). For the 40 isolates selected for phylogenetic analyses, 15 resided in the Prolate Group and 25 isolates formed part of the Sphaero-Naviculate Group. For the MP and ML trees based on the single and combined sequence datasets (TreeBASE no 21167) in Prolate Group or Sphaero-Naviculate Group, although the relative positions of individual Calonectria species differed slightly, while the overall topologies were similar.

Species residing in the Prolate Group: The partition homogeneity tests (PHT) for combinations of the tef1, his3, $c m d A$ and tub2 gene regions yielded a P-value of 0.001 , and consequently, the sequence data for coding gene regions were combined (Cunningham 1997, Dettman et al. 2003). The combined dataset included 51 taxa and consisted of 1993 characters, including alignment gaps, of which 1414 were parsimony-uninformative and 579 were parsimonyinformative. Statistical values for the trees for the MP analyses and parameters for the best-fit substitution models of $\mathrm{ML}$ are provided in Supplementary Table 3. The $\mathrm{ML}$ tree of combined sequence dataset is presented in Fig. 1.

In total, the 15 isolates collected in this study residing in the Prolate Group clustered in three phylogenetic groups (Group A, Group B and Group C), which belong to the Ca. colhounii, Ca. reteaudii and $\mathrm{Ca}$. candelabrum complexes, respectively (Fig. 1). In Group A, five isolates (CMW 47667, CMW 47668, CMW 47669, CMW 47670 and CMW 47671) grouped in a novel monophyletic cluster (ML/MP: 89 \% / 92 $\%$ ) with a single isolate, CMW 47645, forming a novel distinct basal lineage, both of two novel lineages were closely related to, but separate from $\mathrm{Ca}$. monticola and $\mathrm{Ca}$. colhounii (Fig. 1). The total number of the fixed unique differences (SNPs) between the four clades for all four gene regions combined varied between 12-26 (Supplementary Table 4). One isolate (CMW 47660) was identified as Ca. eucalypti (Fig. 1).

In Group B, six isolates (CMW 47270, CMW 47277, CMW 47510, CMW 47628, CMW 47631 and CMW 47635) resided in the same clade as $\mathrm{Ca}$. pentaseptata. Two isolates (CMW 47465 and CMW 47484) clustered within the clade representing Ca. mossambicensis in Group C (Fig. 1).
Species in the Sphaero-Naviculate Group: For this Group, sequences for the tub2 gene region were not available for some taxa due to multiple sequence copies occur in single Calonectira isolates. The PHT comparing the tef1, his 3 and $c m d A$ gene regions gave a $\mathrm{P}=0.077$ value. This showed that there was no significant conflict between the three gene regions and the sequence data for three gene regions were combined (Cunningham 1997, Dettman et al. 2003). The combined sequence dataset included 58 taxa and consisted of 1415 characters, including alignment gaps. Of these, 1015 were parsimony-uninformative and 400 were parsimony-informative. Statistical values for the MP trees and parameters for the best-fit substitution models of $M L$ are provided in Supplementary Table 3. The ML tree is presented in Fig. 2.

The 25 isolates placed in the Sphaero-Naviculate Group of Calonectria collected in this study clustered into three phylogenetic groups (Groups D-F), which all belong to the Ca. kyotensis complex (Fig. 2). Group D included six isolates residing in two distinct sister clades; CMW 47642, CMW 47643 and CMW 47644 in one clade, and CMW 47655, CMW 47656 and CMW 47657 in another clade (ML/MP: $85 \%$ / 80 $\%$, ML/MP: $71 \% / 73 \%$, respectively). Three and four SNPs could be identified in each of the two clades for his3 and tub2 gene sequences (Supplementary Table 5). These two clades were phylogenetically most closely related to $\mathrm{Ca}$. asiatica and $\mathrm{Ca}$. colombiensis (Fig. 2). The total number of SNP differences between isolates in these two clades, $\mathrm{Ca}$. asiatica and Ca. colombiensis, for all four gene regions combined, varied between 7-28 (Supplementary Table 5). Two isolates (CMW 47251 and CMW 47252) formed a single independent clade that was distinct from any known Calonectria species and this was supported by high bootstrap values (ML/MP: $100 \% / 100 \%$ ) (Fig. 2). The total number of SNP differences between this clade accommodating isolates CMW 47251 and CMW 47252, and other phylogenetically closely related Calonectria species (Ca. curvispora, Ca. ilicicola, Ca. pacifica and $\mathrm{Ca}$. sumatrensis) for three gene regions combined varied between 15-44 (Supplementary Table 6). Isolates CMW 47641 and CMW 47654 resided in the clade representing Ca. asiatica, however, with low bootstrap support (Fig. 2). In addition, isolates CMW 47508 and CMW 47637 did not resided in a distinct clade but were closely related to $\mathrm{Ca}$. arbusta (Fig. 2).

In Group E, eight isolates (CMW 47247, CMW 47248, CMW 47488, CMW 47489, CMW 47490, CMW 47496, CMW 47497 and CMW 47498) formed a well-resolved clade (ML/ MP: $81 \% / 98 \%$ ), close to, but distinct from Ca. turangicola (Fig. 2). Several SNPs could be identified for this clade and Ca. turangicola, for three of the four gene regions analysed (Supplementary Table 7). The total number of SNP differences between this clade and the species most closely related to it for all four gene regions combined, varied between 6-34 (Supplementary Table 7). Two isolates, CMW 47257 and CMW 47274 clustered with Ca. hongkongensis (Fig. 2).

In Group F, three isolates (CMW 47256, CMW 47258 and CMW 47259), representing two haplotypes, grouped in a clade, although, lacking bootstrap support. These isolates were most closely related to Ca. chinensis (Fig. 2). 


\section{Prolate Group}

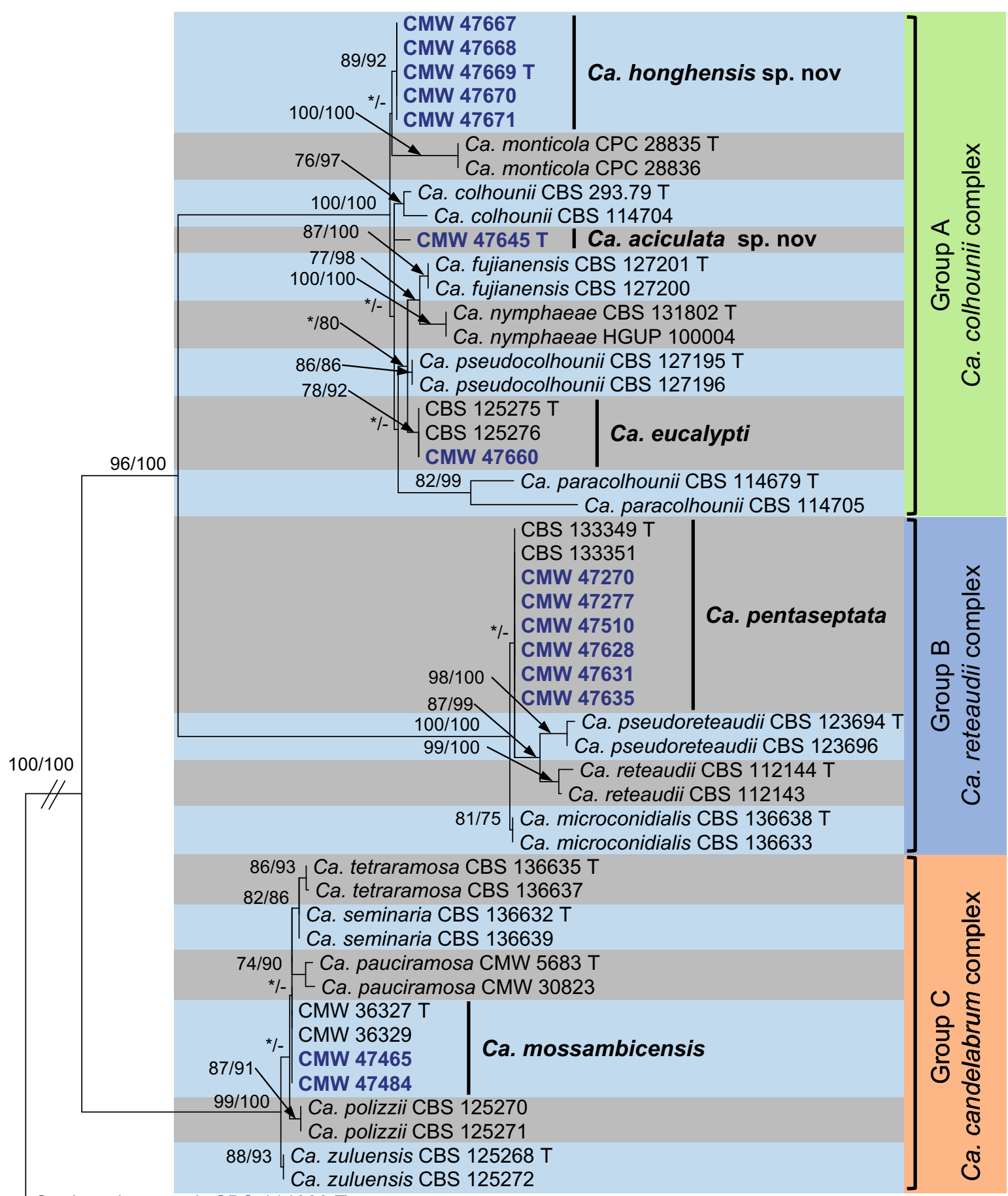

Ca. hongkongensis CBS $114828 \mathrm{~T}$

Ca. hongkongensis CBS 114711

$$
0.05
$$

Fig. 1. Phylogenetic tree based on $M L$ analysis of a combined DNA dataset of tef1, his $3, c m d A$ and tub2 gene sequences for the species of Calonectria in the Prolate Group. Bootstrap value $\geq 70 \%$ for MP and ML analyses are presented at the branches. Bootstrap values lower than $70 \%$ are marked with "*”, and absent are marked with "-". Isolates, representing ex-type material, are marked with "T", isolates sequenced in this study are highlighted in blue and bold. The tree was rooted to Ca. hongkongensis (CBS 114828 and CBS 114711).

\section{Sexual compatibility}

Sixteen isolates belonging to three of the novel taxa ( $\mathrm{Ca}$. honghensis, Ca. pseudoturangicola, and $\mathrm{Ca}$. yunnanensis) 


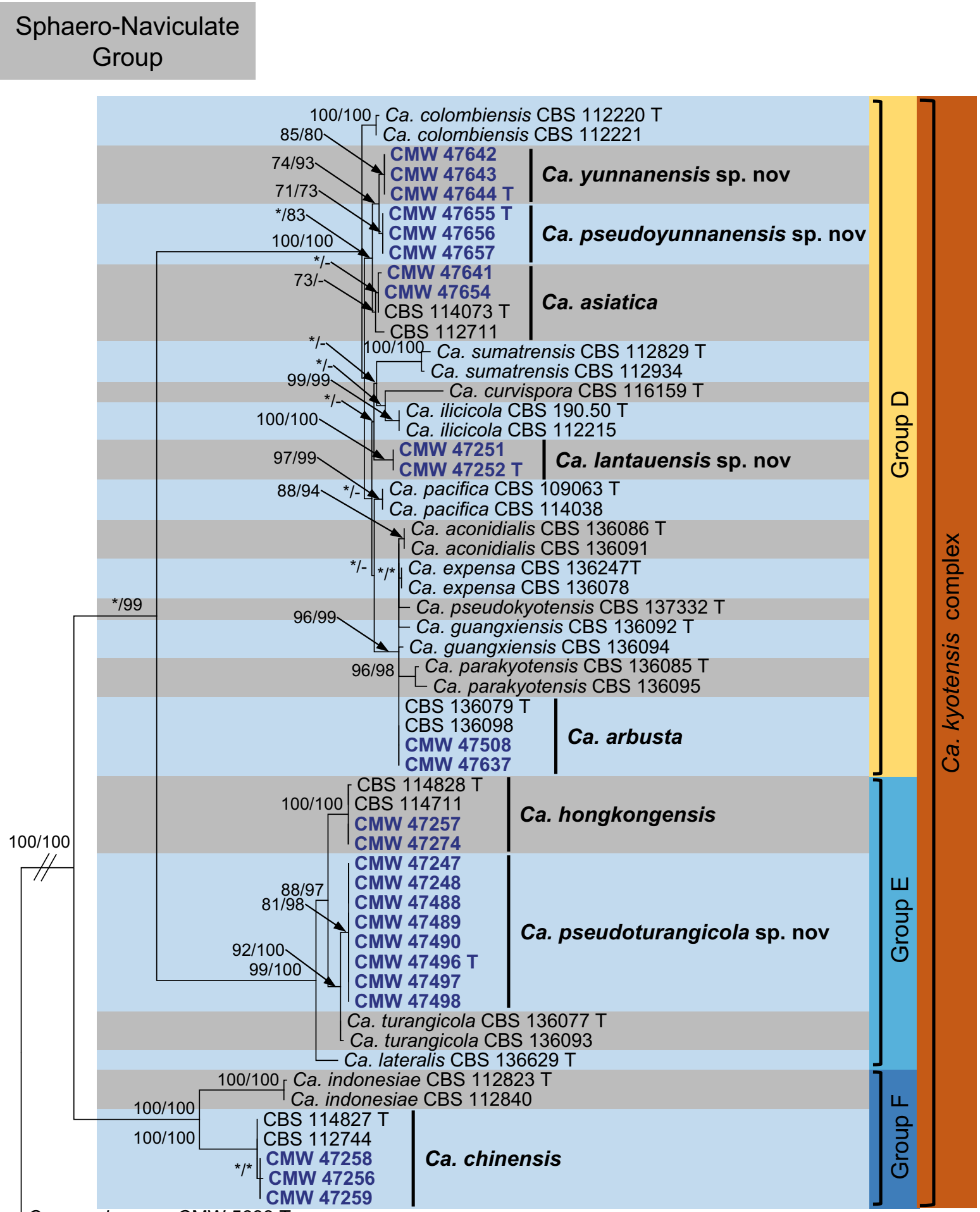

Ca. pauciramosa CMW $5683 \mathrm{~T}$

Ca. pauciramosa CMW 30823

0.05

Fig. 2. Phylogenetic tree based on ML analysis of a combined DNA dataset of tef1, his 3 and $c m d A$ gene sequences for the species of Calonectria in the Sphaero-Naviculate Group. Bootstrap value $\geq 70 \%$ for MP and ML analyses are presented at the branches. Bootstrap values lower than $70 \%$ are marked with "*”, and absent are marked with "-". Isolates, representing ex-type material, are marked with "T", isolates sequenced in this study are highlighted in blue and bold. The tree was rooted to Ca. pauciramosa (CMW 5683 and CMW 30823).

CMW 47642-47644 and CMW 47667-47671 that formed protoperithecia within 2-3 wk and perithecia within 4-6 wk. They were consequently recognised as homothallic. The remaining isolates identified as novel Calonectria species failed to yield any perithecia in crosses, indicating that they were either self-sterile (heterothallic) or they lacked the ability to recombine to produce fertile progeny in culture. 


\section{Morphology and taxonomy}

Based on DNA sequence comparisons (Figs 1-2) and morphology, isolates collected in this study resided in either the Prolate or Sphaero-Naviculate Group of Calonectria species as defined by Lombard et al. (2010c). For the 40 isolates selected for phylogenetic analyses, 18 resolved as known species in six groups and respectively represented Ca. eucalypti (Group A; Ca. colhounii species complex), Ca. pentaseptata (Group B; Ca. reteaudii species complex), Ca. mossambicensis (Group C; Ca. candelabrum species complex), Ca. asiatica and Ca. arbusta (Group D), Ca. hongkongensis (Group $\mathrm{E}$ ) and $\mathrm{Ca}$. chinensis (Group $\mathrm{F}$ ), the latter three groups all clustered in the Ca. kyotensis species complex (Figs 1-2). The former three species resided in the Prolate Group and the latter four known species all clustered in the Sphaero-Naviculate Group (Figs 1-2).

The remaining isolates grouped in six distinct clades (Figs 1-2) that represent novel taxa: Calonectria aciculata and $\mathrm{Ca}$. honghensis spp. nov. in the Prolate Group; and $\mathrm{Ca}$. lantauensis, Ca. pseudoturangicola, Ca. pseudoyunnanensis, and Ca. yunnanensis spp. nov. in Sphaero-Naviculate Group. The morphological characters of isolates identified as new species were compared with the species phylogenetically most closely related to them, and these characteristics are summarized in Table 2. Based on phylogenetic inference and morphological features, these isolates represent six previously undescribed species of Calonectria described below:

\section{TAXONOMY}

\section{Species in the Prolate Group}

Calonectria aciculata J.Q. Li, Q.L. Liu \& S.F. Chen, sp. nov.

MycoBank MB821632

(Fig. 3)

Etymology: After the acicular vesicles in this species.

Diagnosis: Calonectria aciculata can be distinguished from the phylogenetically closely related $\mathrm{Ca}$. colhounii, Ca. honghensis, and $\mathrm{Ca}$. monticola in the longer macroconidia.

Type: China: YunNan Province: PuEr Region, JingGu County, WeiYuan Town, on leaves of an E. urophylla $\times E$. grandis hybrid clone, 16 Nov. 2014, S.F. Chen \& J.Q. Li (PREM 61941 - holotype; CMW 47645 = CERC 5342 = CBS 142883 - ex-type cultures).

Description: Sexual morph unknown. Macroconidiophores consisting of a stipe, a suite of penicillate arranged fertile branches, a stipe extension, and a terminal vesicle; stipe septate, hyaline, smooth, 48-176 × 3-7 $\mu \mathrm{m}$; stipe extensions septate, straight to flexuous 90-193 $\times 2.5-4$ $\mu \mathrm{m}$ long, 2-4 $\mu \mathrm{m}$ wide at the apical septum, terminating in acicular to clavate vesicles, $(2.0-) 2.5-3.5(-5) \mu \mathrm{m}$ diam. Conidiogenous apparatus 19-110 $\mu \mathrm{m}$ long, 27-145 $\mu \mathrm{m}$ wide; primary branches aseptate to 1-septate, 13-38 $\times$
3.5-6 $\mu \mathrm{m}$; secondary branches aseptate, 11-24 $\times 3.5-$ $5.5 \mu \mathrm{m}$; tertiary branches aseptate, 9-14 $\times 3.5-4.5 \mu \mathrm{m}$, each terminal branch producing $2-4$ phialides; phialides doliiform to reniform, hyaline, aseptate, 6-14 × 2.5-5 $\mu \mathrm{m}$, apex with minute periclinal thickening and inconspicuous collarette. Macroconidia cylindrical, rounded at both ends, straight, (53-)62-76(-86) × (4.5-)5-6 (-7) $\mu \mathrm{m}$ (av. = $69 \times$ $5.5 \mu \mathrm{m})$, 3-septate, lacking a visible abscission scar, held in parallel cylindrical clusters by colourless slime. Mega- and microconidia not observed.

Culture characteristics: Colonies forming abundant white aerial mycelium on MEA at $25{ }^{\circ} \mathrm{C}$ after $7 \mathrm{~d}$; moderate sporulation, feathery, irregular margins, reverse pale ochraceous-salmon (13'f) to sanford's brown (11k). Chlamydospores common throughout the medium forming microsclerotia. Growth characteristics, optimal growth temperature $25^{\circ} \mathrm{C}$, no growth at $5^{\circ} \mathrm{C}$ and $35^{\circ} \mathrm{C}$, after $7 \mathrm{~d}$, colonies at $10^{\circ} \mathrm{C}, 15^{\circ} \mathrm{C}, 20^{\circ} \mathrm{C}, 25^{\circ} \mathrm{C}$ and $30^{\circ} \mathrm{C}$ reached $11.3 \mathrm{~mm}, 32.1 \mathrm{~mm}, 48.3 \mathrm{~mm}, 60.3 \mathrm{~mm}$ and $30.8 \mathrm{~mm}$, respectively.

Notes: Calonectria aciculata differs from the phylogenetically closely related species $\mathrm{Ca}$. colhounii, $\mathrm{Ca}$. honghensis, and $\mathrm{Ca}$. monticola with respect to the size of its macroconidia. The average sizes of the macroconidia of Ca. aciculata (av. $=69 \times 5.5 \mu \mathrm{m})$ are longer than the average sizes of $\mathrm{Ca}$. colhounii (av. $=65 \times 5 \mu \mathrm{m})$, Ca. honghensis (av. $=54 \times 5.5$ $\mu \mathrm{m})$ and Ca. monticola (av. $=49 \times 5 \mu \mathrm{m})($ Crous 2002, Crous et al. 2015b).

Calonectria honghensis J.Q. Li, Q.L. Liu \& S.F. Chen, sp. nov.

MycoBank MB821633

(Fig. 4)

Etymology: From the HongHe Region of China where the fungus was first collected.

Diagnosis: Calonectria honghensis differs from the phylogenetically closely related $\mathrm{Ca}$. aciculata, $\mathrm{Ca}$. colhounii and $\mathrm{Ca}$. monticola in the dimensions of the macroconidia and ascospores.

Type: China: YunNan Province: HongHe Region, PingBian County, XinXian Town, from soil collected in a Eucalyptus plantation, 14 Nov. 2014, S.F. Chen \& J.Q. Li (PREM 61943 - holotype; CMW 47669 = CERC 5572 = CBS 142885 - extype cultures).

Description: Perithecia solitary or in groups of up to four, yellow, becoming orange with age; in section apex and body yellow, base red-brown, subglobose to ovoid, 208-423 $\mu \mathrm{m}$ high, 233-406 $\mu \mathrm{m}$ diam, body turning dark yellow, and base dark red in $3 \% \mathrm{KOH}$; perithecial walls rough consisting of two thick-walled layers: outside layer of textura globulosa, 10-57 $\mu \mathrm{m}$ wide, becoming more compressed towards inner layer of textura angularis, 10 $23 \mu \mathrm{m}$ wide, becoming thin-walled and hyaline towards the centre; outer cells $9-41 \times 7-24 \mu \mathrm{m}$, inner cells $10-19$ 

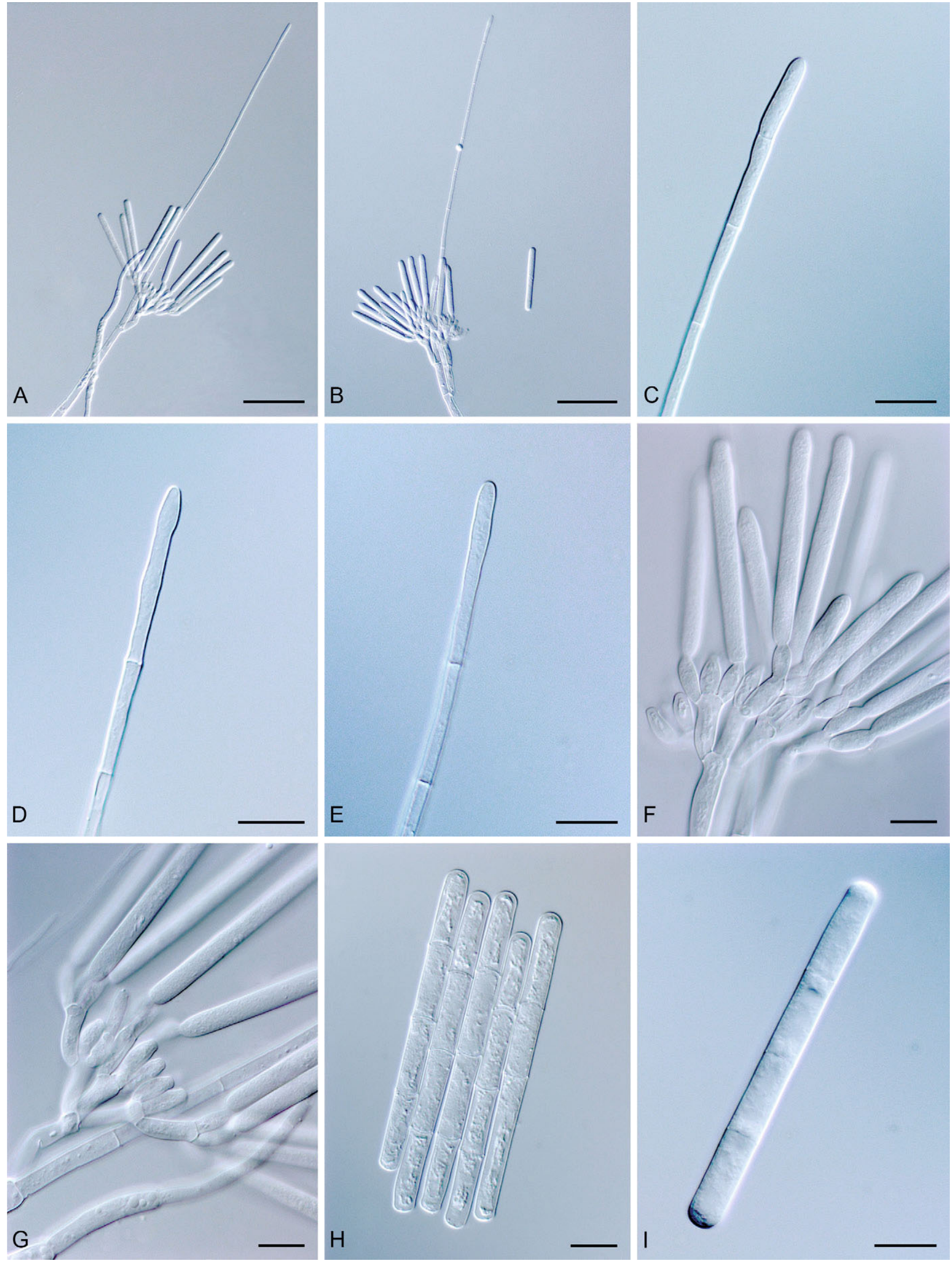

Fig. 3. Calonectria aciculata. A-B. Macroconidiophore. C-E. Acicular to clavate vesicles. F-G. Conidiogenous apparatus with conidiophore branches and doliiform to reniform phialides. H-I. Macroconidia. Bars: A-B $=50 \mu \mathrm{m} ; \mathrm{C}-\mathrm{I}=10 \mu \mathrm{m}$. 

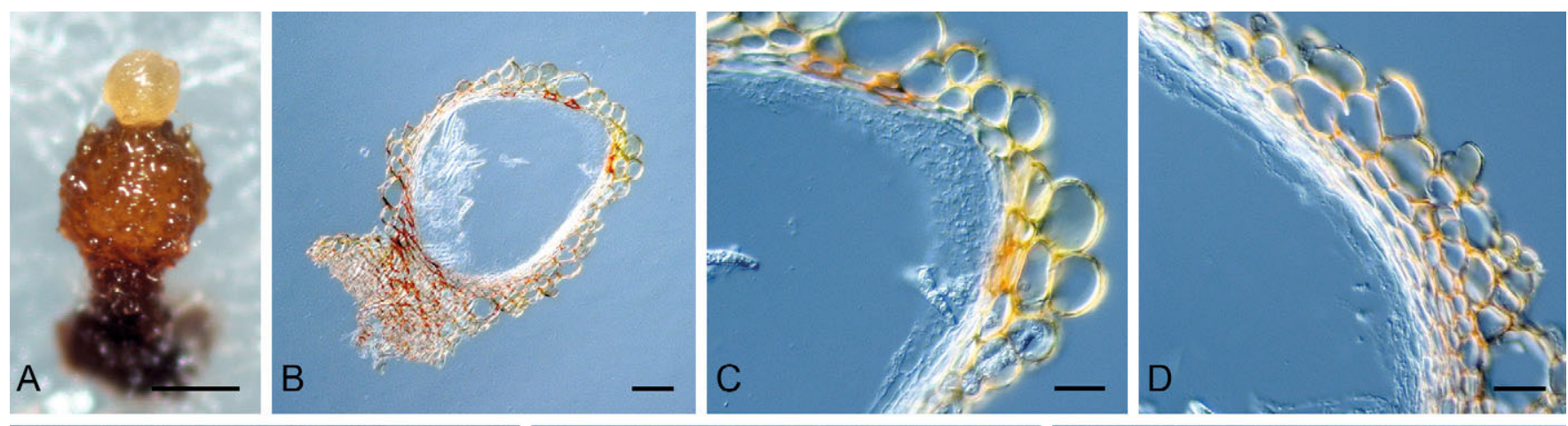

总
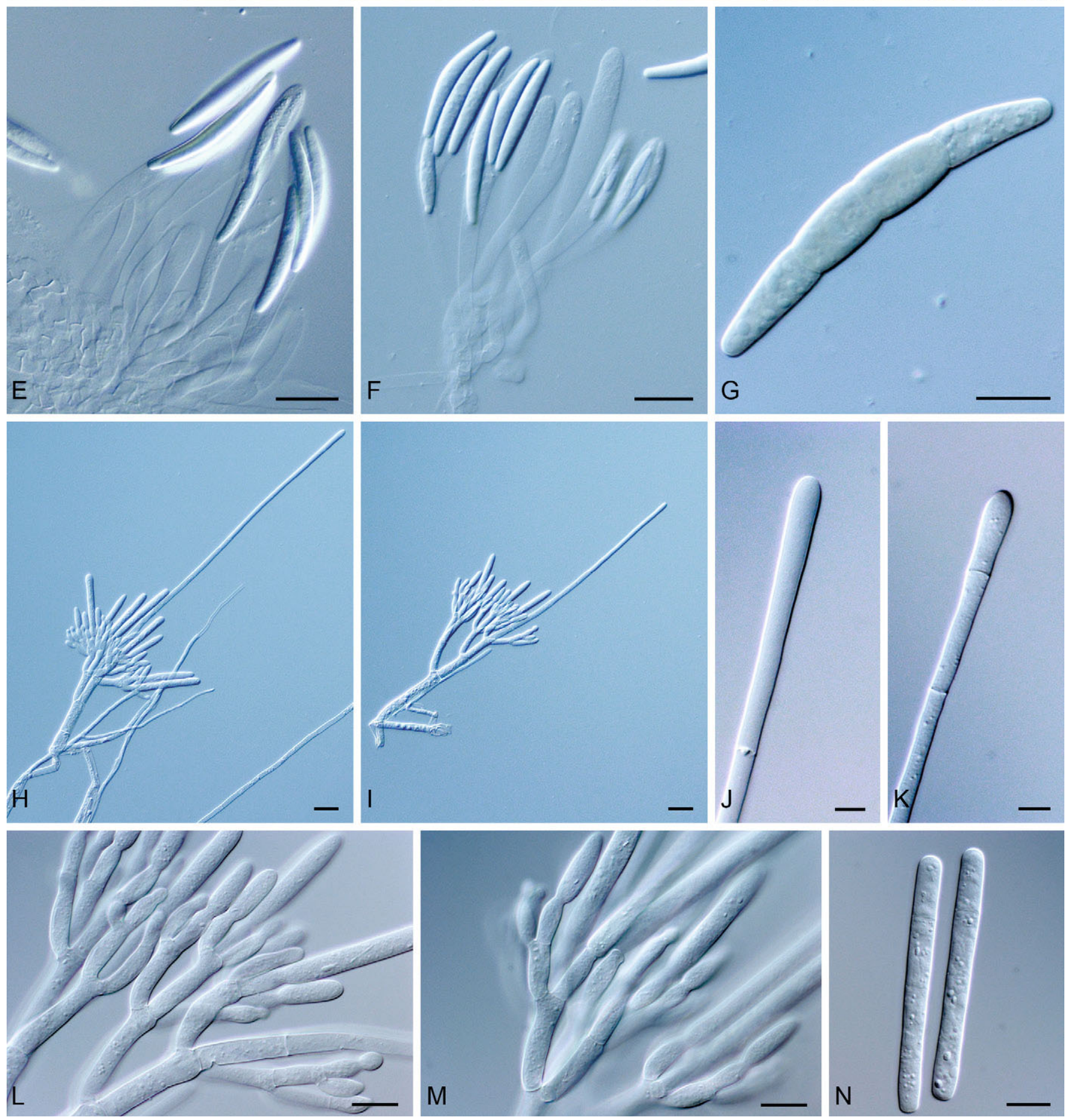

Fig. 4. Calonectria honghensis. A. Perithecium. B. Vertical section through a perithecium. C. Cells around ostiolar region of perithecium. D. Section through lateral perithecial wall. E-F. Asci. G. Ascospores. H-I. Macroconidiophore. J-K. Clavate vesicles. L-M. Conidiogenous apparatus with conidiophore branches and doliiform to reniform phialides. $\mathbf{N}$. Macroconidia. Bars: $A=200 \mu \mathrm{m} ; \mathrm{B}=50 \mu \mathrm{m} ; \mathrm{C}-\mathrm{F}$ and $\mathrm{H}-\mathrm{I}=20$ $\mu \mathrm{m} ; \mathrm{G}$ and $\mathrm{L}-\mathrm{N}=10 \mu \mathrm{m} ; \mathrm{J}$ and $\mathrm{K}=5 \mu \mathrm{m}$. 
ARTICLE

Table 2. Morphological comparisons of Calonectria species examined in this study and other phylogenetically closely related species.

\begin{tabular}{|c|c|c|c|c|c|c|c|c|c|}
\hline Species & $\begin{array}{l}\text { Ascospores } \\
(L \times W)^{1,2}\end{array}$ & $\begin{array}{l}\text { Ascospores } \\
\text { average } \\
(\mathrm{L} \times \mathrm{W})^{1,2}\end{array}$ & $\begin{array}{l}\text { Ascospores } \\
\text { septation }\end{array}$ & Macroconidia $(\mathrm{L} \times \mathrm{W})^{1,2}$ & $\begin{array}{l}\text { Macroconidia } \\
\text { average } \\
(\mathrm{L} \times \mathrm{W})^{1,2} \\
\end{array}$ & $\begin{array}{l}\text { Macroconidia } \\
\text { septation }\end{array}$ & $\begin{array}{l}\text { Vesicle } \\
(\text { Min.-Max.) })^{3}\end{array}$ & Vesicle shape & Reference \\
\hline Ca. aciculata ${ }^{4}$ & $N / A^{5}$ & $\mathrm{~N} / \mathrm{A}$ & $\mathrm{N} / \mathrm{A}$ & $\begin{array}{l}(53-) 62-76(-86) \times \\
(4.5-) 5-6(-7)^{6}\end{array}$ & $69 \times 5.5$ & 3 & $(2-) 2.5-3.5(-5)$ & acicular to clavate & This study \\
\hline Ca. honghensis & $\begin{array}{l}(35-) 43-55(-65) \times \\
(4.5-) 5.5-6.5(-7.5)\end{array}$ & $49 \times 6$ & 3 & $\begin{array}{l}(43-) 49-59(-66) \times \\
(4.5-) 5-5.5(-6)\end{array}$ & $54 \times 5.5$ & 3 & $\begin{array}{l}(2.5-) 3-4.5(- \\
5.5)\end{array}$ & clavate & This study \\
\hline Ca. colhounii & $\begin{array}{l}(30-) 50-65(-75) \times \\
(4-) 5-6(-8)\end{array}$ & $55 \times 6$ & $(1-) 3$ & $\begin{array}{l}(45-) 60-70(-80) \times \\
(4-) 5-(-6)\end{array}$ & $65 \times 5$ & $(1-) 3$ & $3-4$ & clavate & Crous (2002) \\
\hline Ca. monticola & N/A & $\mathrm{N} / \mathrm{A}$ & N/A & $46-51(-56) \times 4-6(-7)$ & $49 \times 5$ & 3 & $4-6$ & broadly clavate & Crous et al. (2015b) \\
\hline Ca. Iantauensis & $\mathrm{N} / \mathrm{A}$ & $\mathrm{N} / \mathrm{A}$ & N/A & $\begin{array}{l}(49-) 52-58(-62) \times \\
(4.5-) 5-5.5(-6)\end{array}$ & $55 \times 5$ & 1 & $\begin{array}{l}(7.5-) 8.5- \\
12.5(-17.5)\end{array}$ & sphaeropedunculate & This study \\
\hline Ca. curvispora & $\mathrm{N} / \mathrm{A}$ & $\mathrm{N} / \mathrm{A}$ & $\mathrm{N} / \mathrm{A}$ & $\begin{array}{l}(45-) 55-65(-70) \times \\
(4-) 5-6\end{array}$ & $60 \times 5$ & $1(-3)$ & $(5-) 8(-10)$ & sphaeropedunculate & Crous (2002) \\
\hline Ca. ilicicola & $\begin{array}{l}(30-) 37-50(-65) \times \\
(4-) 5-6.5(-7)\end{array}$ & $45 \times 6$ & $1(-3)$ & $\begin{array}{l}(45-) 70-82(-90) \times \\
(4-) 5-6.5(-7)\end{array}$ & $62 \times 6$ & $(1-)^{3}$ & $(6-) 7-10(-12)$ & sphaeropedunculate & Crous (2002) \\
\hline Ca. pacifica & N/A & $\mathrm{N} / \mathrm{A}$ & $\mathrm{N} / \mathrm{A}$ & $(38-) 45-65(-75) \times 4-5$ & $55 \times 4.5$ & 1 & $7-15$ & sphaeropedunculate & Crous (2002) \\
\hline Ca. sumatrensis & $\mathrm{N} / \mathrm{A}$ & $\mathrm{N} / \mathrm{A}$ & N/A & $\begin{array}{l}(45-) 55-65(-70) \times \\
(4.5) 5(-6)\end{array}$ & $58 \times 5$ & 1 & $8-13$ & sphaeropedunculate & Crous et al. (2004) \\
\hline Ca. pseudoturangicola & $\begin{array}{l}(24-) 27-35(-43) \times \\
(4.5-) 5.5-7.5(-9.5)\end{array}$ & $31 \times 6.5$ & $1(-3)$ & $\begin{array}{l}(33-) 36-44(-50) \times \\
(2.5-) 3.5-4\end{array}$ & $40 \times 3.5$ & 1 & $\begin{array}{l}(4.5-) 5-8.5(- \\
12)\end{array}$ & sphaeropedunculate & This study \\
\hline Ca. hongkongensis & $\begin{array}{l}(25-) 28-35(-40) \times \\
(4-) 5-6(-7)\end{array}$ & $31 \times 6$ & 1 & $\begin{array}{l}(38-) 45-48(-53) \times \\
4(-4.5)\end{array}$ & $46.5 \times 4$ & 1 & $8-14$ & sphaeropedunculate & Crous et al. (2004) \\
\hline Ca. turangicola & N/A & $\mathrm{N} / \mathrm{A}$ & $\mathrm{N} / \mathrm{A}$ & $(40-) 42-46(-47) \times 3-5$ & $44 \times 4$ & 1 & $8-12$ & sphaeropedunculate & Lombard et al. (2015) \\
\hline Ca. pseudoyunnanensis & $\mathrm{N} / \mathrm{A}$ & $\mathrm{N} / \mathrm{A}$ & N/A & $\begin{array}{l}(40-) 44-50(-55) \times \\
(4-) 4.5-5.5(-6)\end{array}$ & $47.5 \times 5$ & 1 & $(2.5-) 3.5-5$ & $\begin{array}{l}\text { ellipsoidal, } \\
\text { obpyriform to } \\
\text { sphaeropedunculate }\end{array}$ & This study \\
\hline Ca. yunnanensis & $\begin{array}{l}(28-) 31-41(-55) \times \\
(5-) 5.5-6.5(-8)\end{array}$ & $36 \times 6$ & $1(-3)$ & $\begin{array}{l}(36-) 39-47(-52) \times \\
(4-) 4.5-5(-5.5)\end{array}$ & $43 \times 4.5$ & 1 & $\begin{array}{l}(2-) 2.5-3.5(- \\
4.5)\end{array}$ & sphaeropedunculate & This study \\
\hline Ca. asiatica & $\begin{array}{l}(28-) 30-38(-40) \times \\
(5-) 6(-7)\end{array}$ & $33 \times 6$ & 1 & $\begin{array}{l}(42-) 48-55(-65) \times \\
(4-) 5(-5.5)\end{array}$ & $53 \times 5$ & 1 & $12-17$ & sphaeropedunculate & Crous et al. (2004) \\
\hline Ca. colombiensis & $\begin{array}{l}(28-) 30-35(-40) \times \\
(4-) 5(-6)\end{array}$ & $33 \times 5$ & 1 & $\begin{array}{l}(33-) 48-58(-60) \times \\
(4-) 4.5(-5)\end{array}$ & $53 \times 4.5$ & $1(-3)$ & $7-12$ & sphaeropedunculate & Crous et al. (2004) \\
\hline
\end{tabular}

${ }^{1}$ All measurements are in $\mu \mathrm{m}$.

${ }^{2} \mathrm{~L} \times \mathrm{W}=$ length $\times$ width.

${ }^{3}$ Min.-Max. $=$ minimum-maximum.

${ }^{4}$ Species indicated in bold are described in this study.

${ }^{5} \mathrm{~N} / \mathrm{A}=$ not available.

${ }^{6}$ Measurements are presented in the format [(minimum-) (average - standard deviation)-(average + standard deviation) $(-$ maximum)]. 
$\times 3-13 \mu \mathrm{m}$, perithecial base to $190 \mu \mathrm{m}$ wide, consisting of dark red, angular cells merging with an erumpent stroma, cells of the outer wall layer continuing into the pseudoparenchymatous cells of the erumpent stroma. Asci 4-spored, clavate, (75-)91-115(-153) × (13-)14-24(-37) $\mu \mathrm{m}(\mathrm{av} .=103 \times 19 \mu \mathrm{m})$, tapering to a long thin stalk. Ascospores aggregate in the upper third of the asci, hyaline, guttulate, fusoid with rounded ends, straight to slightly curved, 3-septate, not or slightly constricted at the septum, $(35-) 43-55(-65) \times(4.5-) 5.5-6.5(-7.5) \mu \mathrm{m}(\mathrm{av} .=49 \times 6$ $\mu \mathrm{m})$. Macroconidiophores consisting of a stipe, a suite of penicillate arranged fertile branches, a stipe extension, and a terminal vesicle; stipe septate, hyaline, smooth, 42-192 × 4-10 $\mu \mathrm{m}$; stipe extensions septate, straight to flexuous, $70-215 \mu \mathrm{m}$ long, 3-5 $\mu \mathrm{m}$ wide at the apical septum, terminating in a clavate vesicle, (2.5-)3.0-4.5(5.5) $\mu \mathrm{m}$ diam. Conidiogenous apparatus 33-114 $\mu \mathrm{m}$ long, 21-75 $\mu \mathrm{m}$ wide; primary branches aseptate to 1-septate, 14-57 × 4-7.5 $\mu \mathrm{m}$; secondary branches aseptate, 10-26 $\times 4-5.5 \mu \mathrm{m}$; tertiary branches aseptate, 9-19 × 3.5-6 $\mu \mathrm{m}$; additional branches (-4), aseptate, 9.5-14.5 × 3.5-5 $\mu \mathrm{m}$; each terminal branch producing $2-4$ phialides; phialides doliiform to reniform, hyaline, aseptate, 7-12 × 3-5 $\mu \mathrm{m}$, apex with minute periclinal thickening and inconspicuous collarette. Macroconidia cylindrical, rounded at both ends, straight, (43-)49-59(-66) × (4.5-)5-5.5(-6) $\mu \mathrm{m}$ (av. = $54 \times$ $5.5 \mu \mathrm{m})$, 3-septate, lacking a visible abscission scar, held in parallel cylindrical clusters by colourless slime. Megaand microconidia not observed.

Culture characteristics: Colonies forming white to sienna aerial mycelium on MEA at $25{ }^{\circ} \mathrm{C}$ after $7 \mathrm{~d}$, profuse sporulation, feathery, irregular margins, reverse capucine buff (13f) to umber (9). Chlamydospores common throughout the medium forming microsclerotia. Growth characteristics, optimal growth temperature $25^{\circ} \mathrm{C}$, no growth at $5^{\circ} \mathrm{C}$ and 35 ${ }^{\circ} \mathrm{C}$, after $7 \mathrm{~d}$, colonies at $10^{\circ} \mathrm{C}, 15^{\circ} \mathrm{C}, 20^{\circ} \mathrm{C}, 25^{\circ} \mathrm{C}$ and 30 ${ }^{\circ} \mathrm{C}$ reached $14.3 \mathrm{~mm}, 31.6 \mathrm{~mm}, 43.5 \mathrm{~mm}, 51.9 \mathrm{~mm}$ and 17.3 $\mathrm{mm}$, respectively.

Additional material examined: China: YunNan Province: HongHe Region, PingBian County, XinXian Town: from soil collected in a Eucalyptus plantation, 14 Nov. 2014, S.F. Chen \& J.Q. Li (PREM 61942, culture CMW 47668 = CERC 5571 = CBS 142884; PREM 61944, culture CMW 47670 = CERC 5573 = CBS 142886).

Notes: Calonectria honghensis is phylogenetically most closely related to $\mathrm{Ca}$. aciculata, Ca. colhounii, and $\mathrm{Ca}$. monticola. However, $\mathrm{Ca}$. honghensis can be distinguished from these species by the dimensions of the macroconidia and ascospores. The average size of the macroconidia of $\mathrm{Ca}$. honghensis (av. $=54 \times 5.5 \mu \mathrm{m}$ ) is shorter than that of $\mathrm{Ca}$. aciculata (av. $=69 \times 5.5 \mu \mathrm{m})$ and Ca. colhounii (av. $=65 \times 5$ $\mu \mathrm{m})$, but longer than that of Ca. monticola (av. $=49 \times 5 \mu \mathrm{m}$ ) (Crous 2002, Crous et al. 2015b). The average size of the ascospores of $\mathrm{Ca}$. honghensis (av. $=49 \times 6 \mu \mathrm{m}$ ) is shorter than for Ca. colhounii (av. $=55 \times 6 \mu \mathrm{m})$ (Crous 2002); sexual structures are not known for $\mathrm{Ca}$. aciculata and $\mathrm{Ca}$. monticola (Crous et al. 2015b).

\section{Species in the Sphaero-Naviculate Group}
Calonectria lantauensis J.Q. Li, Q.L. Liu \& S.F. Chen, sp. nov.

MycoBank MB821634

(Fig. 5)

Etymology: After Lantau Island in Hong Kong, China, where the fungus was first collected.

Diagnosis: Calonectria lantauensis can be distinguished from the phylogenetically closely related species $\mathrm{Ca}$. curvispora, Ca. ilicicola, Ca. pacifica and Ca. sumatrensis by the size of the macroconidia.

Type: China: Hong Kong Region: LiDao Distict, Lantau Island, from soil collected in roadside near Hong Kong airport, 12 Mar. 2014, M.J. Wingfield \& S.F. Chen (PREM 61946 - holotype; CMW 47252 = CERC 3302 = CBS 142888 - ex-type cultures).

Description: Sexual morph unknown. Macroconidiophores consisting of a stipe, a suite of penicillate arranged fertile branches, a stipe extension, and a terminal vesicle; stipe septate, hyaline, smooth, 44-216 × 4.5-12.5 $\mu \mathrm{m}$; stipe extension septate, straight to flexuous $51-271 \mu \mathrm{m}$ long, 2-5.5 $\mu \mathrm{m}$ wide at the apical septum, terminating in a sphaeropedunculate vesicle, (7.5-)8.5-12.5(-17.5) $\mu \mathrm{m}$ diam; lateral stipe extensions absent. Conidiogenous apparatus 45-173 $\mu \mathrm{m}$ long, 34-114 $\mu \mathrm{m}$ wide; primary branches aseptate to 1-septate, $16-83 \times 4.5-12.5 \mu \mathrm{m}$; secondary branches aseptate, $10-19 \times 4.5-7.5 \mu \mathrm{m}$; tertiary branches aseptate, 7.5-13 × 3.5-6 $\mu \mathrm{m}$; each terminal branch producing 2-6 phialides; phialides doliiform to reniform, hyaline, aseptate, 5.5-13 × 3-8 $\mu \mathrm{m}$; apex with minute periclinal thickening and inconspicuous collarette. Macroconidia cylindrical, rounded at both ends, straight, (49-)52-58(-62) × (4.5-)5-5.5(-6) $\mu \mathrm{m},($ av. $=55 \times 5 \mu \mathrm{m}), 1$-septate, lacking a visible abscission scar, held in parallel cylindrical clusters by colourless slime. Mega- and microconidia not observed.

Culture characteristics: Colonies forming abundant white to buff aerial mycelium on MEA at $25{ }^{\circ} \mathrm{C}$ after $7 \mathrm{~d}$, moderate sporulation, feathery, irregular margins, reverse sienna (8) to umber (9). Growth characteristic, optimal growth temperature $25^{\circ} \mathrm{C}$, no growth at $5^{\circ} \mathrm{C}$ and $35^{\circ} \mathrm{C}$, after $7 \mathrm{~d}$, colonies at 10 ${ }^{\circ} \mathrm{C}, 15^{\circ} \mathrm{C}, 20^{\circ} \mathrm{C}, 25^{\circ} \mathrm{C}$ and $30^{\circ} \mathrm{C}$ reached $7.2 \mathrm{~mm}, 28.8 \mathrm{~mm}$, $54.2 \mathrm{~mm}, 78.0 \mathrm{~mm}$ and $71.6 \mathrm{~mm}$, respectively.

Additional material examined: China: Hong Kong Region: LiDao Distict, Lantau Island, from soil collected in roadside near Hong Kong airport, 12 Mar. 2014, M.J. Wingfield \& S.F. Chen (PREM 61945, culture CMW $47251=$ CERC $3301=$ CBS 142887).

Notes: Calonectria lantauensis is closely related to $\mathrm{Ca}$. curvispora, Ca. ilicicola, Ca. pacifica, and $\mathrm{Ca}$. sumatrensis. Calonectria lantauensis can be distinguished from $\mathrm{Ca}$. curvispora, Ca. ilicicola and Ca. sumatrensis by the average size of the macroconidia. The macroconidia of Ca. lantauensis (av. $=55 \times 5 \mu \mathrm{m})$ are shorter than those of 

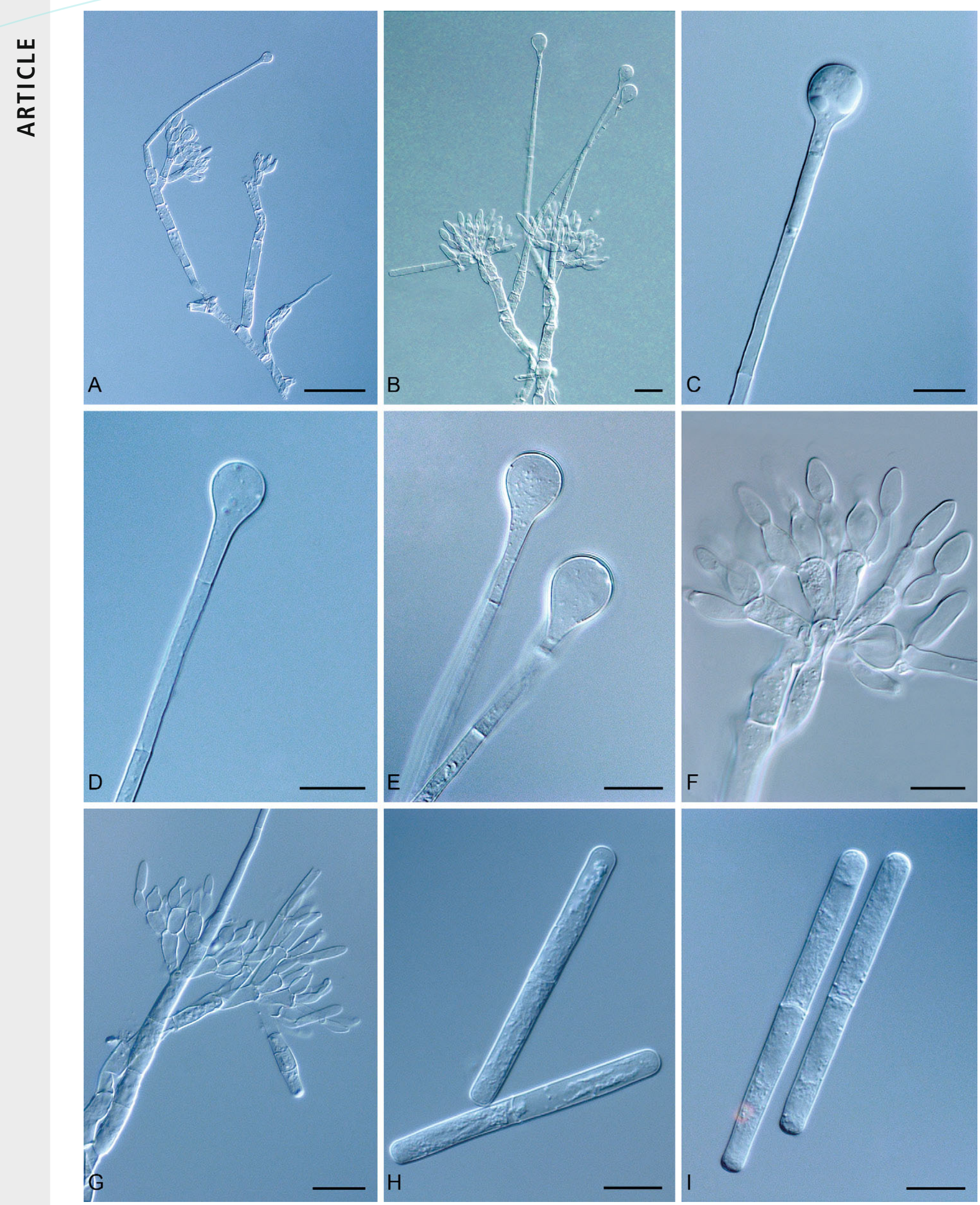

Fig. 5. Calonectria lantauensis. A-B. Macroconidiophore. C-E. Sphaeropedunculate vesicles. F-G. Conidiogenous apparatus with conidiophore branches and doliiform to reniform phialides. $\mathrm{H}-\mathrm{I}$. Macroconidia. Bars: $\mathrm{A}=50 \mu \mathrm{m} ; \mathrm{B}$ and $\mathrm{G}=20 \mu \mathrm{m} ; \mathrm{C}-\mathrm{F}$ and $\mathrm{H}-\mathrm{I}=10 \mu \mathrm{m}$. 
Ca. curvispora (av. $=60 \times 5 \mu \mathrm{m})$, Ca. ilicicola (av. $=62 \times 6$ $\mu \mathrm{m})$ and Ca. sumatrensis (av. $=58 \times 5 \mu \mathrm{m})($ Crous 2002, Crous et al. 2004). No lateral stipe extensions were found in Ca. lantauensis, Ca. curvispora or Ca. ilicicola, while these structures are commonly observed in $\mathrm{Ca}$. pacifica but rarely observed in Ca. sumatrensis (Crous 2002, Crous et al. 2004).

Calonectria pseudoturangicola J.Q. Li, Q.L. Liu \& S.F. Chen, sp. nov.

MycoBank MB821635

(Fig. 6)

Etymology: From the close resemblance to Calonectria turangicola.

Diagnosis: Calonectria pseudoturangicola can be distinguished from the phylogenetically closely related species $\mathrm{Ca}$. hongkongensis and $\mathrm{Ca}$. turangicola in the shorter and narrower macroconidia.

Type: China: FuJian Province: FuZhou City, CangShan District, from soil collected in the campus of Fujian Agriculture and Forestry University (FAFU), 14 Dec. 2014, S.F. Chen (PREM 61948 - holotype; CMW 47496 = CERC 7126 = CBS 142890 - ex-type cultures).

Description: Perithecia solitary or in groups of up to five, orange, becoming orange-brown with age; in section, apex and body orange, base red-brown, subglobose to ovoid, 241-511 $\mu \mathrm{m}$ high, 242-456 $\mu \mathrm{m}$ diam, body turning red, and base dark red-brown in $3 \% \mathrm{KOH}$; perithecial walls rough consisting of two thick-walled layers: outside layer of textura globulosa, 21-49 $\mu \mathrm{m}$ wide, becoming more compressed towards inner layer of textura angularis, 8-16 $\mu \mathrm{m}$ wide, becoming thin-walled and hyaline towards the centre; outer cells $17-60 \times 10-33 \mu \mathrm{m}$, inner cells $7-44 \times 2-15 \mu \mathrm{m}$; perithecial base to $191 \mu \mathrm{m}$ wide, consisting of dark red, angular cells merging with an erumpent stroma, cells of the outer wall layer continuing into the pseudoparenchymatous cells of the erumpent stroma. Asci 8-spored, clavate, (71-) 84-114(-142) × (8-)11-17(-22) $\mu \mathrm{m}($ av. = $99 \times 14 \mu \mathrm{m})$, tapering to a long thin stalk. Ascospores aggregate in the upper third of the asci, hyaline, guttulate, fusoid with rounded ends, straight to slightly curved, 1(-3)-septate, not or slightly constricted at the septum, (24-)27-35(-43) × (4.5-)5.5-7.5(9.5) $\mu \mathrm{m}(\mathrm{av} .=31 \times 6.5 \mu \mathrm{m})$. Macroconidiophores consisting of a stipe, a suite of penicillate arranged fertile branches, a stipe extension, and a terminal vesicle; stipe septate, hyaline, smooth, 32-146 × 3.5-7.5 $\mu \mathrm{m}$; stipe extension septate, straight to flexuous $35-217 \mu \mathrm{m}$ long, $1.5-3.5 \mu \mathrm{m}$ wide at the apical septum, terminating in a sphaeropedunculate vesicle, (4.5-)5-8.5(-12) $\mu \mathrm{m}$ diam; lateral stipe extensions $\left(90^{\circ}\right.$ to main axis) abundant, septate, straight to flexuous $21-143$ $\mu \mathrm{m}$ long, terminating in a sphaeropedunculate vesicle, 1-4 $\mu \mathrm{m}$ diam. Conidiogenous apparatus 32-187 $\mu \mathrm{m}$ long, 23-126 $\mu \mathrm{m}$ wide; primary branches aseptate to 1-septate, $13-53 \times 3.5-6 \mu \mathrm{m}$; secondary branches aseptate, 11-28 $\times 3-5.5 \mu \mathrm{m}$; tertiary branches aseptate, 8.5-21 × 3-5 $\mu \mathrm{m}$; additional branches (-5), aseptate, 6-11.5 × 2-4.5 $\mu \mathrm{m}$; each terminal branch producing $2-4$ phialides; phialides doliiform to reniform, hyaline, aseptate, 7-13.5 × 2-4.5 $\mu \mathrm{m}$, apex with minute periclinal thickening and inconspicuous collarette. Macroconidia cylindrical, rounded at both ends, straight, (33-)

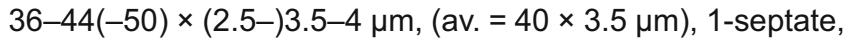
lacking a visible abscission scar, held in parallel cylindrical clusters by colourless slime. Mega- and microconidia not observed.

Culture characteristics: Colonies forming abundant white to saffron aerial mycelium on MEA at $25^{\circ} \mathrm{C}$ after $7 \mathrm{~d}$, profuse sporulation, feathery, irregular margins, reverse capucine buff (13f) to russet $\left(13^{\prime} k\right)$. Chlamydospores common throughout the medium forming microsclerotia. Growth characteristics, optimal growth temperature $25^{\circ} \mathrm{C}$, no growth at $5^{\circ} \mathrm{C}$ and 35 ${ }^{\circ} \mathrm{C}$, after $7 \mathrm{~d}$, colonies at $10^{\circ} \mathrm{C}, 15^{\circ} \mathrm{C}, 20^{\circ} \mathrm{C}, 25^{\circ} \mathrm{C}$ and 30 ${ }^{\circ} \mathrm{C}$ reached $9.3 \mathrm{~mm}, 28.9 \mathrm{~mm}, 43.3 \mathrm{~mm}, 68.7 \mathrm{~mm}$ and 57.2 $\mathrm{mm}$, respectively.

Additional material examined: China: FuJian Province: Fuzhou City, MinHou County, BaiSha Town: from soil collected in a Eucalyptus plantation, 12 Dec. 2014, S.F. Chen (PREM 61947, culture CMW $47489=$ CERC 7115 = CBS 142889); FuZhou City, CangShan District: from soil collected in the campus of Fujian Agriculture and Forestry University (FAFU), 14 Dec. 2014, S.F. Chen (PREM 61949, culture CMW $47497=$ CERC $7127=$ CBS 142891).

Notes: Calonectria pseudoturangicola is phylogenetically closely related to $\mathrm{Ca}$. hongkongensis and $\mathrm{Ca}$. turangicola, but the macroconidia of Ca. pseudoturangicola (av. $=40$ $\times 3.5 \mu \mathrm{m})$ are shorter and narrower than those of $\mathrm{Ca}$. hongkongensis (av. $=46.5 \times 4 \mu \mathrm{m})$ and $\mathrm{Ca}$. turangicola (av. = $44 \times 4 \mu \mathrm{m})($ Crous et al. 2004, Lombard et al. 2015).

Calonectria pseudoyunnanensis J.Q. Li, Q.L. Liu \& S.F. Chen, sp. nov. MycoBank MB821636

(Fig. 7)

Etymology: From the close resemblance to Calonectria yunnanensis.

Diagnosis: Calonectria pseudoyunnanensis can be distinguished from the phylogenetically closely related $\mathrm{Ca}$. asiatica, $\mathrm{Ca}$. colombiensis, and $\mathrm{Ca}$. yunnanensis by the size of macroconidia and the shape of vesicles.

Type: China: YunNan Province: PuEr Region, JingGu County, WeiYuan Town, from soil collected in a Eucalyptus plantation, 16 Nov. 2014, S.F. Chen \& J.Q. Li (PREM 61950 - holotype; CMW $47655=$ CERC $5376=$ CBS $142892-$ ex-type cultures).

Description: Sexual morph unknown. Macroconidiophores consisting of a stipe, a suite of penicillate arranged fertile branches, a stipe extension, and a terminal vesicle; stipe septate, hyaline, smooth, 38-89 × 5-8 $\mu \mathrm{m}$; stipe extension septate, straight to flexuous 22-94 $\mu \mathrm{m}$ long, $1.5-2.5 \mu \mathrm{m}$ wide at the apical septum, terminating in ellipsoidal, obpyriform to sphaeropedunculate vesicles, (2.5-)3.5-5.0 $\mu \mathrm{m}$ diam; lateral stipe extensions ( $90^{\circ}$ to main axis) abundant, septate, straight to flexuous $18-64 \mu \mathrm{m}$ long, terminating in a obpyriform to 

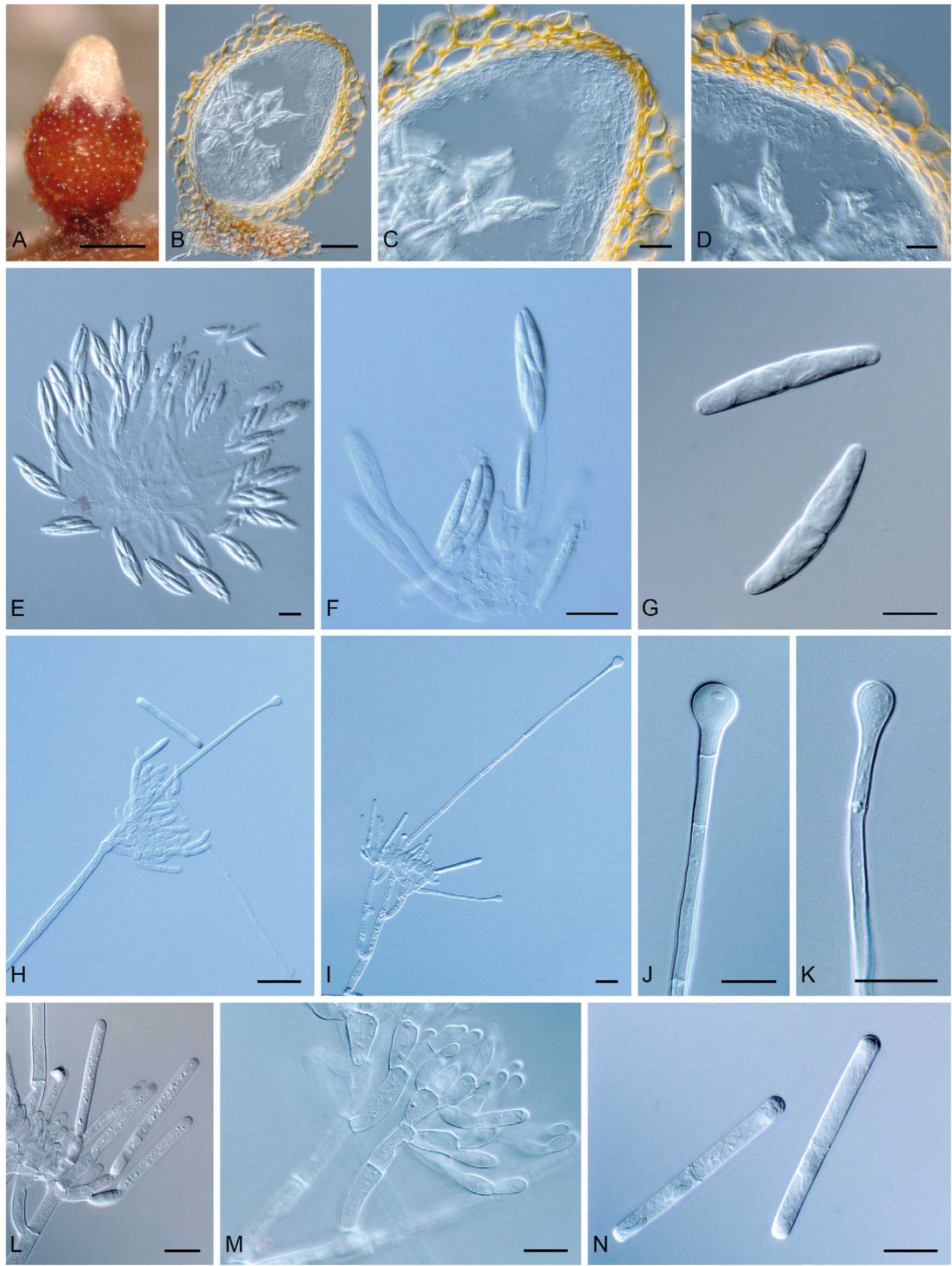

Fig. 6. Calonectria pseudoturangicola. A. Perithecium. B. Vertical section through a perithecium. C. Cells around ostiolar region of perithecium. D. Section through lateral perithecial wall. E-F. Asci. G. Ascospores. H-I. Macroconidiophore. J-K. Sphaeropedunculate vesicles. L-M. Conidiogenous apparatus with conidiophore branches and doliiform to reniform phialides. N. Macroconidia. Bars: $A=200 \mu \mathrm{m} ; B=50 \mu \mathrm{m} ; \mathrm{C}-\mathrm{F}$ and $\mathrm{H}-\mathrm{I}=20 \mu \mathrm{m} ; \mathrm{G}$ and $\mathrm{J}-\mathrm{N}=10 \mu \mathrm{m}$. 

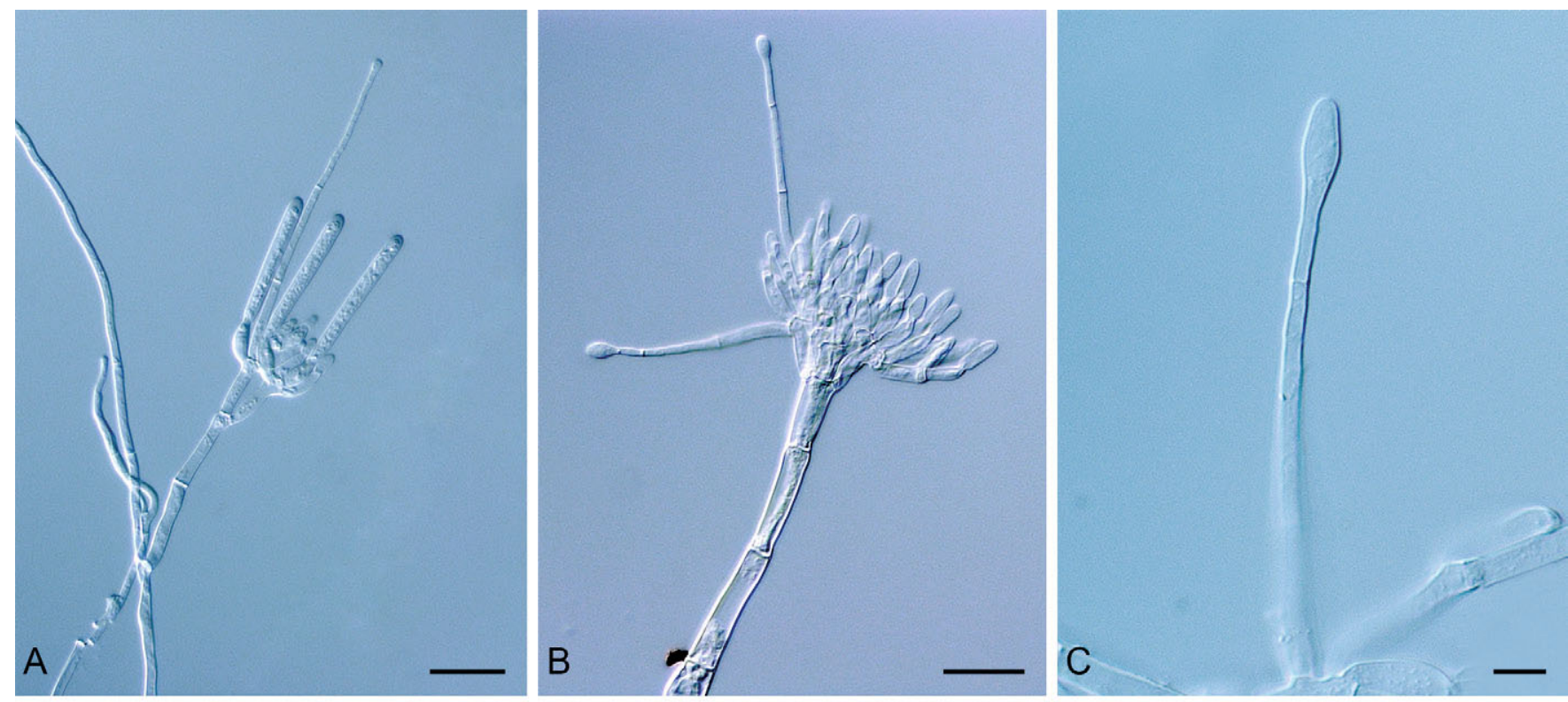

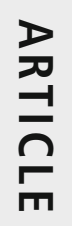
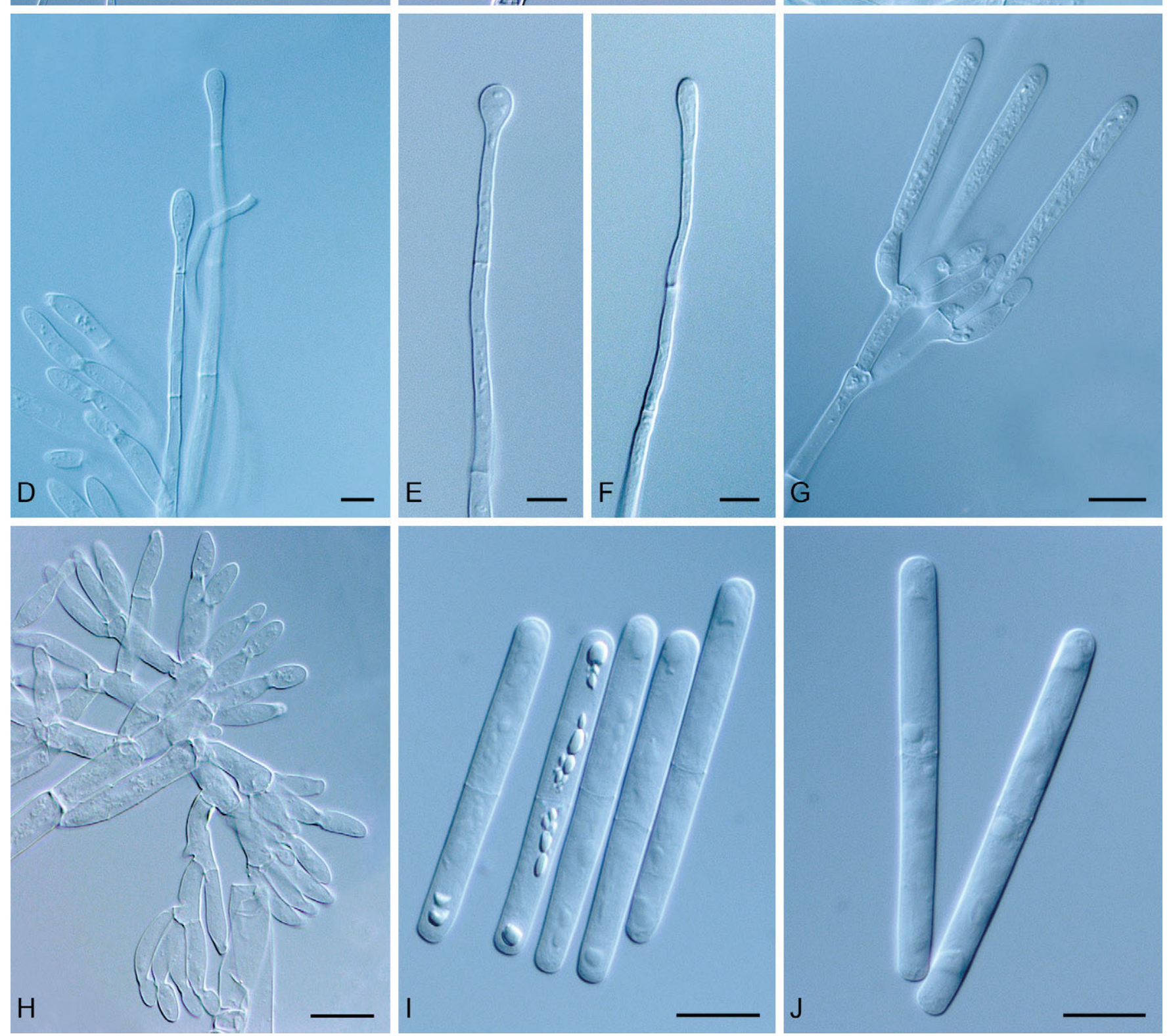

Fig. 7. Calonectria pseudoyunnanensis. A-B. Macroconidiophore. C-F. Ellipsoidal, obpyriform to sphaeropedunculate vesicles. G-H. Conidiogenous apparatus with conidiophore branches and doliiform to reniform phialides. I-J. Macroconidia. Bars: A-B = $20 \mu \mathrm{m} ; \mathrm{G}-\mathrm{J}=10 \mu \mathrm{m}$; $\mathrm{C}-\mathrm{F}=5 \mu \mathrm{m}$. 
sphaeropedunculate vesicle, 1-3 $\mu \mathrm{m}$ diam. Conidiogenous apparatus $28-87 \mu \mathrm{m}$ long, 32-83 $\mu \mathrm{m}$ wide; primary branches aseptate to 1-septate, $16-42 \times 3.5-6.5 \mu \mathrm{m}$; secondary branches aseptate, $11-19 \times 3.5-5.5 \mu \mathrm{m}$; tertiary branches aseptate, $7-13 \times 3-5 \mu \mathrm{m}$; each terminal branch producing $2-4$ phialides; phialides doliiform to reniform, hyaline, aseptate, 6-15 × 3-5 $\mu \mathrm{m}$; apex with minute periclinal thickening and inconspicuous collarette. Macroconidia cylindrical, rounded at both ends, straight, (40-)44-50(-55) × (4-)4.5-5.5(-6) $\mu \mathrm{m}$ $($ av. $=47.5 \times 5 \mu \mathrm{m}), 1$-septate, lacking a visible abscission scar, held in parallel cylindrical clusters by colourless slime. Mega- and microconidia not observed.

Culture characteristics: Colonies forming abundant white aerial mycelium on MEA at $25{ }^{\circ} \mathrm{C}$ after $7 \mathrm{~d}$, moderate sporulation, feathery, irregular margins, reverse pale yelloworange (15f) to sienna (8). Chlamydospores common throughout the medium forming microsclerotia. Growth characteristics, optimal growth temperature $25^{\circ} \mathrm{C}$, no growth at $5{ }^{\circ} \mathrm{C}$ and $35^{\circ} \mathrm{C}$, after $7 \mathrm{~d}$, colonies at $10^{\circ} \mathrm{C}, 15^{\circ} \mathrm{C}, 20^{\circ} \mathrm{C}$, $25^{\circ} \mathrm{C}$ and $30^{\circ} \mathrm{C}$ reached $6.4 \mathrm{~mm}, 30.4 \mathrm{~mm}, 53.7 \mathrm{~mm}, 78.4$ $\mathrm{mm}$ and $55.3 \mathrm{~mm}$, respectively.

Additional material examined: China: YunNan Province: PuEr Region, JingGu County, WeiYuan Town, from soil collected in a Eucalyptus plantation, 16 Nov. 2014, S.F. Chen \& J.Q. Li (PREM 61951, CMW 47656 = CERC 5377 = CBS 142893; PREM 61952, culture CMW 47657 = CERC 5378 = CBS 142894).

Notes: Calonectria pseudoyunnanensis is most closely related to $\mathrm{Ca}$. asiatica, Ca. colombiensis, and Ca. yunnanensis. It can be distinguished from these three species by the average size of the macroconidia. Those of Ca. pseudoyunnanensis (av. $=47.5$ $\times 5 \mu \mathrm{m}$ ) are longer and broader than those of $\mathrm{Ca}$. yunnanensis (av. $=43 \times 4.5 \mu \mathrm{m})$, but shorter than those of Ca. asiatica (av. = $53 \times 5 \mu \mathrm{m})$ and Ca. colombiensis (av. $=53 \times 4.5 \mu \mathrm{m})$ (Crous et al. 2004). Furthermore, the vesicle shape of $C a$. pseudoyunnanensis (ellipsoidal, obpyriform to sphaeropedunculate) is different to those of $\mathrm{Ca}$. asiatica (sphaeropedunculate) and $\mathrm{Ca}$. colombiensis (sphaeropedunculate) (Crous et al. 2004, Lombard et al. 2010c).

Calonectria yunnanensis J.Q. Li, Q.L. Liu \& S.F. Chen, sp. nov.

MycoBank MB821637

(Fig. 8)

Etymology: From YunNan Province, China, where this fungus was first collected.

Diagnosis: Calonectria yunnanensis can be distinguished from the phylogenetically closely related $\mathrm{Ca}$. asiatica, $\mathrm{Ca}$. colombiensis, and Ca. pseudoyunnanensis by the size of macroconidia and ascospores.

Type: China: YunNan Province: PuEr Region, JingGu County, ZhengXing Town, from soil collected in a Eucalyptus plantation, 16 Nov. 2014, S.F. Chen \& J.Q. Li (PREM 61955 - holotype; CMW 47644 = CERC 5339 = CBS 142897 - extype cultures).
Description: Perithecia solitary or in groups of up to five, orange, becoming orange-brown with age; in section, apex and body orange, base red-brown, subglobose to ovoid, 303-511 $\mu \mathrm{m}$ high, 322-567 $\mu \mathrm{m}$ diam, body turning red, and base dark red-brown in $3 \% \mathrm{KOH}$; perithecial walls rough consisting of two thick-walled layers: outside layer of textura globulosa, 24-72 $\mu \mathrm{m}$ wide, becoming more compressed towards inner layer of textura angularis, 10-22 $\mu \mathrm{m}$ wide, becoming thin-walled and hyaline towards the centre; outer cells 19-37 x 12-21 $\mu \mathrm{m}$, inner cells $14-39 \times 3-11 \mu \mathrm{m}$; perithecial base up to $260 \mu \mathrm{m}$ wide, consisting of dark red, angular cells merging with an erumpent stroma, cells of the outer wall layer continuing into the pseudoparenchymatous cells of the erumpent stroma. Asci 8-spored, clavate, (84) $97-133(-163) \times(10-) 15-21(-27) \mu \mathrm{m}($ av. $=115 \times 18 \mu \mathrm{m})$, tapering to a long thin stalk. Ascospores aggregate in the upper third of the asci, hyaline, guttulate, fusoid with rounded ends, straight to slightly curved, 1(-3)-septate, not or slightly constricted at the septum, (28-)31-41(-55) × (5-)5.5-6.5(8) $\mu \mathrm{m}(\mathrm{av} .=36 \times 6 \mu \mathrm{m})$. Macroconidiophores consisting of a stipe, a suite of penicillate arranged fertile branches, a stipe extension, and a terminal vesicle; stipe septate, hyaline, smooth, $43-230 \times 2.5-7 \mu \mathrm{m}$; stipe extension septate, straight to flexuous $25-102 \mu \mathrm{m}$ long, $1.5-3.5 \mu \mathrm{m}$ wide at the apical septum, terminating in a sphaeropedunculate vesicle, (2-)2.5-3.5(-4.5) $\mu \mathrm{m}$ diam; lateral stipe extensions $\left(90^{\circ}\right.$ to main axis) abundant, septate, straight to flexuous 25-69 $\mu \mathrm{m}$ long, terminating in a sphaeropedunculate vesicle, 1-4 $\mu \mathrm{m}$ diam. Conidiogenous apparatus 20-130 $\mu \mathrm{m}$ long, 23-135 $\mu \mathrm{m}$ wide; primary branches aseptate to 1-septate, 13-49 × 3-6.5 $\mu \mathrm{m}$; secondary branches aseptate, 12-17 $\times 3-5 \mu \mathrm{m}$; tertiary branches aseptate, 4-13 × 1.5-4 $\mu \mathrm{m}$; each terminal branch producing 2-4 phialides; phialides doliiform to reniform, hyaline, aseptate, 6-16 × 2.5-4.5 $\mu \mathrm{m}$, apex with minute periclinal thickening and inconspicuous collarette. Macroconidia cylindrical, rounded at both ends, straight, (36-)39-47(-52) x (4-)4.5-5(-5.5) $\mu \mathrm{m},(\mathrm{av} .=43 \times$ $4.5 \mu \mathrm{m}), 1$-septate, lacking a visible abscission scar, held in parallel cylindrical clusters by colourless slime. Mega- and microconidia not observed.

Culture characteristics: Colonies forming abundant white to white-buff aerial mycelium on MEA at $25^{\circ} \mathrm{C}$ after $7 \mathrm{~d}$, profuse sporulation, feathery, irregular margins, reverse salmon (13'd) to sienna (8). Chlamydospores common throughout the medium forming microsclerotia. Growth characteristics, optimal growth temperature $25^{\circ} \mathrm{C}$, no growth at $5^{\circ} \mathrm{C}$ and 35 ${ }^{\circ} \mathrm{C}$, after $7 \mathrm{~d}$, colonies at $10^{\circ} \mathrm{C}, 15^{\circ} \mathrm{C}, 20^{\circ} \mathrm{C}, 25^{\circ} \mathrm{C}$ and 30 ${ }^{\circ} \mathrm{C}$ reached $7.3 \mathrm{~mm}, 33.0 \mathrm{~mm}, 53.9 \mathrm{~mm}, 76.4 \mathrm{~mm}$ and 53.9 $\mathrm{mm}$, respectively.

Additional material examined: China: YunNan Province: PuEr Region, JingGu County, ZhengXing Town, from soil collected in a Eucalyptus plantation, 16 Nov. 2014, S.F. Chen \& J.Q. Li (PREM 61953, culture CMW 47642 = CERC 5337 = CBS 142895; PREM 61954, culture CMW $47643=$ CERC $5338=$ CBS 142896).

Notes: Calonectria yunnanensis is closely related to Ca. asiatica, Ca. colombiensis and Ca. pseudoyunnanensis. It can be distinguished from these three species by the 

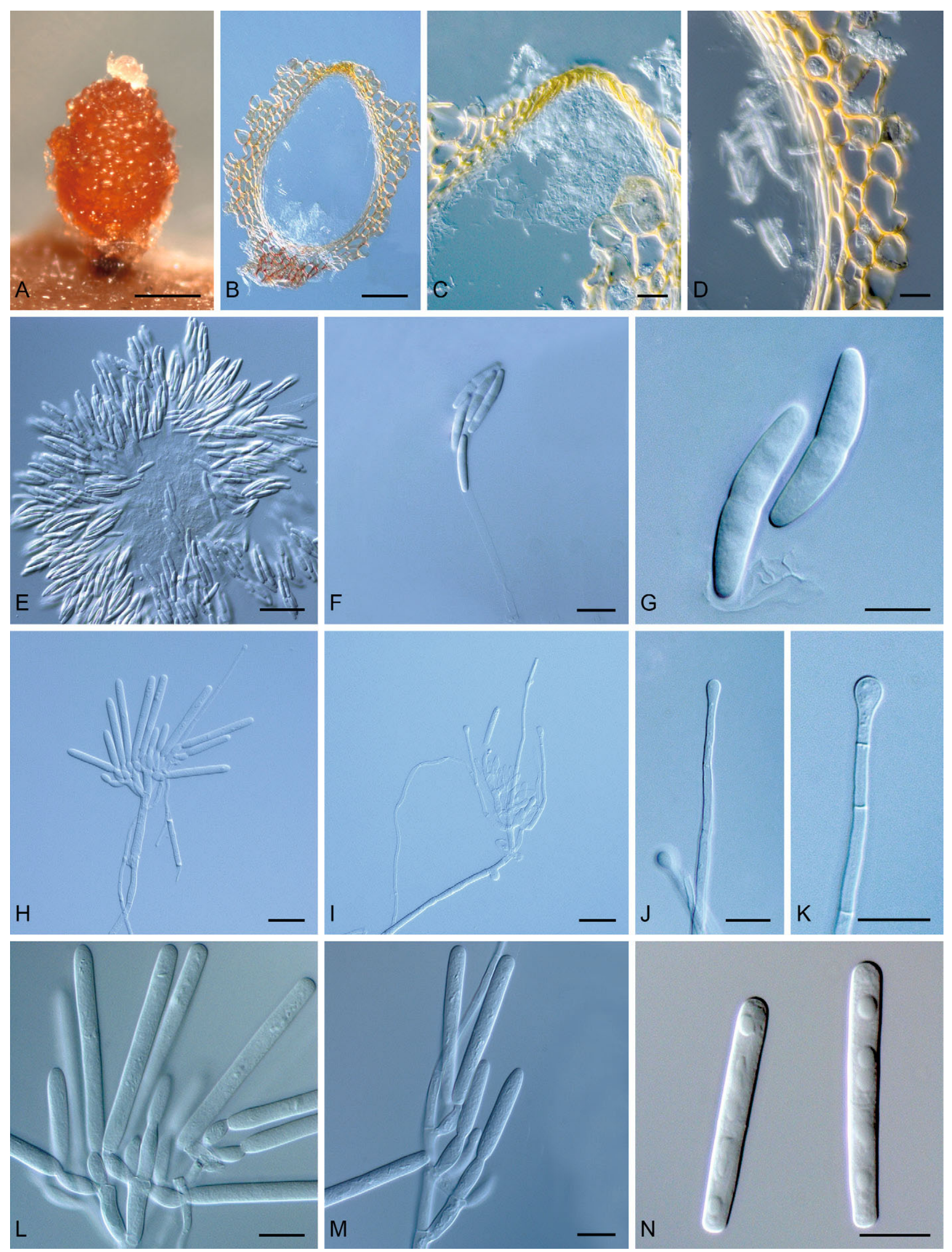

Fig. 8. Calonectria yunnanensis. A. Perithecium. B. Vertical section through a perithecium. C. Cells around ostiolar region of perithecium. D. Section through lateral perithecial wall. E-F. Asci. G. Ascospores. H-I. Macroconidiophore. J-K. Sphaeropedunculate vesicles. L-M. Conidiogenous apparatus with conidiophore branches and doliiform to reniform phialides. $\mathbf{N}$. Macroconidia. Bars: $A=200 \mu \mathrm{m} ; \mathrm{B}=100 \mu \mathrm{m} ; \mathrm{E}=$ $50 \mu \mathrm{m} ; \mathrm{C}-\mathrm{D}, \mathrm{F}$ and $\mathrm{H}-\mathrm{I}=20 \mu \mathrm{m} ; \mathrm{G}$ and $\mathrm{J}-\mathrm{N}=10 \mu \mathrm{m}$. 
average size of the macroconidia. The macroconidia of $\mathrm{Ca}$. yunnanensis (av. $=43 \times 4.5 \mu \mathrm{m}$ ) are shorter than those of $\mathrm{Ca}$. asiatica (av. $=53 \times 5 \mu \mathrm{m})$, Ca. colombiensis (av. $=53 \times 4.5$ $\mu \mathrm{m})$ and Ca. pseudoyunnanensis (av. $=47.5 \times 5 \mu \mathrm{m})$ (Crous et al. 2004). The ascospores of Ca. yunnanensis (av. $=36 \times$ $6 \mu \mathrm{m}$ ) are slightly longer than those of Ca. asiatica (av. $=33$ $\times 6 \mu \mathrm{m}$ ) and Ca. colombiensis (av. $=33 \times 5 \mu \mathrm{m})$ (Crous et al. 2004).

\section{DISCUSSION}

Results of this study revealed 13 species of Calonectria from infected Eucalyptus tissues collected in plantations and nurseries, or baited soil samples from Eucalyptus plantations, and a naturally forested area in South China. These species include Ca. arbusta, Ca. asiatica, Ca. chinensis, Ca. eucalypti, $\mathrm{Ca}$. hongkongensis, Ca. mossambicensis, $\mathrm{Ca}$. pentaseptata, and six previously undescribed taxa ( $\mathrm{Ca}$. aciculata, Ca. honghensis, Ca. lantauensis, Ca. pseudoturangicola, Ca. pseudoyunnanensis, and Ca. yunnanensis). The six novel species were strongly supported by DNA sequence data and morphological observations. Five of the 13 species, including $\mathrm{Ca}$. aciculata, Ca. eucalypti, Ca. honghensis, Ca. mossambicensis, and $\mathrm{Ca}$. pentaseptata, resided in the Prolate Group and eight in the Sphaero-Naviculate Group. With the exception of the newly described species, this is the first report of Ca. asiatica, Ca. eucalypti, and Ca. mossambicensis from China. Calonectria chinensis and $\mathrm{Ca}$. lantauensis were isolated only from soil in natural forested areas, while 11 species were all collected from Eucalyptus plantations or nurseries.

Calonectria pentaseptata, identified in this study, resides in the $\mathrm{Ca}$. reteaudii species complex and was widely distributed in different regions causing disease on Eucalyptus in plantations and nurseries in South China. Amongst the 115 Calonectria isolates collected in this study, approximately half (57) were identified as $\mathrm{Ca}$. pentaseptata, and this fungus occurred at six different sites in the GuangDong and GuangXi Provinces. This is consistent with previous studies showing that $C a$. pentaseptata is widely distributed in Eucalyptus plantations and nurseries in South China (Lombard et al. 2015). The Ca. reteaudii complex, which includes species that are well-known causal agents of Calonectria Leaf Blight (CLB) of Eucalyptus (Crous 2002, Rodas et al. 2005, Lombard et al. 2010b). Calonectria pentaseptata is the fourth species in the Ca. reteaudii species complex to have been found in China; the other three include Ca. crousiana, Ca. microconidialis and $\mathrm{Ca}$. pseudoreteaudii. Pathogenicity tests have shown that all four of these species cause rot on inoculated Eucalyptus leaves (Chen et al. 2011c, Li et al. 2014a, b). Overall, the results of this study support the view (Lombard et al. 2015) that Ca. pentaseptata is an important Eucalyptus pathogen both in plantations and nurseries in China.

Calonectria mossambicensis is the fourth species in the $\mathrm{Ca}$. candelabrum complex to have been reported from China together with $\mathrm{Ca}$. pauciramosa, Ca. seminaria and Ca. tetraramosa. All four species were isolated from diseased seedlings in Eucalyptus nurseries (Lombard et al. 2010d, 2015). Species in the Ca. candelabrum complex include some important nursery pathogens (Crous 2002, Lombard et al. 2010b, d, Guarnaccia et al. 2014, Alfenas et al. 2015). Inoculation studies have also shown that $C a$. pauciramosa, $C a$. seminaria and $\mathrm{Ca}$. tetraramosa are differentially pathogenic to Eucalyptus clones (Chen et al. 2011c, Li et al. 2014a, b). Calonectria mossambicensis was originally described from diseased cuttings of $E$. grandis $\times E$. camaldulensis clones in Mozambique (Crous et al. 2013) and it is likely to be a Eucalyptus nursery pathogen in China, since this fungus causes rot on Eucalyptus cutting rot in Mozambique.

Three species residing in the $\mathrm{Ca}$. colhounii complex were identified in this study. They include $\mathrm{Ca}$. eucalypti and the newly described $\mathrm{Ca}$. aciculata and $\mathrm{Ca}$. honghensis. Species in the Ca. colhounii complex are characterized by bright yellow perithecia (Crous 2002, Lombard et al. 2010c, Chen et al. 2011c, Xu et al. 2012). Calonectria aciculata and $\mathrm{Ca}$. honghensis are closely related to $\mathrm{Ca}$. colhounii and these three species can easily be distinguished from each other based on phylogenetic inference, as well as by their macroconidial dimensions. Other Calonectria species known in China and that reside in the Ca. colhounii complex include Ca. fujianensis, Ca. nymphaeae, and $\mathrm{Ca}$. pseudocolhounii (Chen et al. 2011c, Xu et al. 2012). Other than Ca. honghensis isolated from soil collected in a Eucalyptus plantation, and Ca. nymphaeae from diseased leaves of Nymphaea tetragona (Xu et al. 2012), the remaining four species in the Ca. colhounii complex were all isolated from diseased Eucalyptus leaves in commercial plantations (Chen et al. 2011c). Inoculation studies have shown that Ca. crousiana, Ca. fujianensis and $\mathrm{Ca}$. pseudocolhounii are all pathogenic to inoculated Eucalyptus clones (Chen et al. 2011c, Li et al. 2014a, b).

Four new species in the Sphaero-Naviculate Group reside in the $\mathrm{Ca}$. kyotensis complex, Ca. lantauensis, Ca. pseudoturangicola, Ca. pseudoyunnanensis, and Ca. yunnanensis. Calonectria pseudoyunnanensis and Ca. yunnanensis are sister species based on phylogenetic inference but they can easily be distinguished by DNA sequence comparisons of the his 3 and tub2 gene regions, and vesicle shape differences. Calonectria pseudoturangicola appears as a sister species to Ca. turangicola but can be distinguished based on DNA sequence differences in the tef1, cmdA and tub2 gene regions, and macroconidial dimensions (Lombard et al. 2015). Calonectria lantauensis formed a basal clade in the Ca. kyotensis species complex, and lateral stipe extensions were absent in this species making it readily distinguishable from other species in the Ca. kyotensis species complex (Crous et al. 2004, Lombard et al. 2010c, 2015).

The remaining four known species (Ca. arbusta, Ca. asiatica, Ca. chinensis, and $\mathrm{Ca}$. hongkongensis) found in this study reside in the $\mathrm{Ca}$. kyotensis complex. To date, 19 species in the Ca. kyotensis complex have been found in China and the only other species in the complex, Ca. asiatica, was first described from Thailand (Crous et al. 2004, Lombard et al. 2015). These 19 species were all isolated exclusively from soil (Lombard et al. 2015) and the results of this study suggest that many more species in this complex have yet to be discovered from soil in China.

Overall, the results of this study revealed 37 species 
of Calonectria from China. Other than Ca. asiatica, Ca. eucalypti, Ca. mossambicensis, Ca. pauciramosa, and Ca. pentaseptata, all of these species were first discovered in this country (Crous et al. 2004, Lombard et al. 2010d, 2015, Chen et al. 2011c, Xu et al. 2012). The results highlight the significant impact that DNA sequence comparisons have had in revealing new species of filamentous fungi, including species of Calonectria (Lombard et al. 2010c, 2015, 2016, Crous et al. 2015a).

With the exception of $\mathrm{Ca}$. nymphaeae isolated from diseased leaves of $N$. tetragona (Xu et al. 2012), and Ca. lantauensis from a naturally forested area in Hong Kong, all of the other 35 species found in China were from Eucalyptus plantations or nurseries. This appears to be an environment surprisingly rich in species of Calonectria, although future sampling in China should be expanded to include other environments. Inoculation tests conducted in previous studies have shown that 15 species of Calonectria found in China are pathogenic to several Eucalyptus clones (Chen et al. 2011c, Li et al. 2014a, b). Future work should include a more comprehensive understanding of the species diversity, distribution, pathogenicity and population biology of Calonectria in China. This will contribute to the development of integrated management strategies for the diseases caused by these fungi in Eucalyptus plantations and nurseries.

\section{ACKNOWLEDGEMENTS}

This study was supported by the National Natural Science Foundation of China (NSFC) (Project Numbers 31622019, 31400546). The authors acknowledge members of Tree Protection and Cooperation Programme (TPCP). The authors thank GuoQing Li, FeiFei Liu, and $\mathrm{MiRu}$ Zhang for their assistance in collecting samples.

\section{REFERENCES}

Alfenas RF, Lombard L, Pereira OL, Alfenas AC, Crous PW (2015) Diversity and potential impact of Calonectria species in Eucalyptus plantations in Brazil. Studies in Mycology 80: 89-130.

Brown BN, Ferreira FA (2000) Disease during Propagation of Eucalypts. Canberra: CSIRO publishing.

Burgess TI, Andjic V, Hardy GS, Dell B, Xu D (2006) First report of Phaeophleospora destructans in China. Journal of Tropical Forest Science 18: 144-146.

Burgess TI, Barber PA, Sufaati S, Xu D, Hardy GS, et al. (2007) Mycosphaerella spp. on Eucalyptus in Asia: new species, new hosts and new records. Fungal Diversity 24: 135-157.

Chen SF, Gryzenhout M, Roux J, Xie YJ, Wingfield MJ, et al. (2010) Identification and pathogenicity of Chrysoporthe cubensis on Eucalyptus and Syzygium spp. in South China. Plant Disease 94: 1143-1150.

Chen SF, Barnes I, Chungu D, Roux J, Wingfield MJ, et al. (2011a) High population diversity and increasing importance of the Eucalyptus stem canker pathogen, Teratosphaeria zuluensis, in South China. Australasian Plant Pathology 40: 407-415.

Chen SF, Gryzenhout M, Roux J, Xie YJ, Wingfield MJ, et al. (2011b) Novel species of Celoporthe from Eucalyptus and Syzygium trees in China and Indonesia. Mycologia 103: 1384-1410.
Chen SF, Lombard L, Roux J, Xie YJ, Wingfield MJ, et al. (2011c) Novel species of Calonectria associated with Eucalyptus leaf blight in Southeast China. Persoonia 26: 1-12.

Chen SF, Pavlic D, Roux J, Slippers B, Xie YJ, et al. (2011d) Characterization of Botryosphaeriaceae from plantation-grown Eucalyptus species in South China. Plant Pathology 60: 739751.

Chen SF, Van Wyk M, Roux J, Wingfield MJ, Xie YJ, et al. (2013) Taxonomy and pathogenicity of Ceratocystis species on Eucalyptus trees in South China, including C. chinaeucensis sp. nov. Fungal Diversity 58: 267-279.

Chen SX, Chen XF (2013) Technical problems and thinking on eucalypt plantation management in China. Eucalypt Science \& Technology 30: 52-59. [In Chinese]

Cortinas MN, Burgess T, Dell B, Xu D, Crous PW, et al. (2006) First record of Colletogloeopsis zuluense comb. nov., causing a stem canker of Eucalyptus in China. Mycological Research 110: 229236.

Crous PW (2002) Taxonomy and Pathology of Cylindrocladium (Calonectria) and allied genera. St Paul, MN: American Phytopathological Society Press.

Crous PW, Groenewald JZ, Risède JM, Simoneau P, Hywel-Jones $\mathrm{NL}$ (2004) Calonectria species and their Cylindrocladium anamorphs: species with sphaeropedunculate vesicles. Studies in Mycology 50: 415-430.

Crous PW, Phillips AJL, Wingfield MJ (1991) The genera Cylindrocladium and Cylindrocladiella in South Africa, with special reference to forest nurseries. South African Forestry Journal 157: 69-85.

Crous PW, Shivas RG, Wingfield MJ, Summerell BA, Rossman AY, et al. (2012) Fungal Planet description sheets: 128-153. Persoonia 29: 146-201.

Crous PW, Wingfield MJ, Guarro J, Cheewangkoon R, Van der Bank $\mathrm{M}$, et al. (2013) Fungal Planet description sheets: 154-213. Persoonia 31: 188-296.

Crous PW, Hawksworth DL, Wingfield MJ (2015a) Identifying and naming plant-pathogenic fungi: past, present, and future. Annual Review of Phytopathology 53: 247-267.

Crous PW, Wingfield MJ, Le Roux JJ, Richardson DM, Strasberg D, et al. (2015b) Fungal Planet description sheets: 371-399. Persoonia 35: 264-327.

Cunningham CW (1997) Can three incongruence tests predict when data should be combined? Molecular Biology and Evolution 14: 733-740.

Dettman JR, Jacobson DJ, Taylor JW (2003) A multilocus genealogical approach to phylogenetic species recognition in the model eukaryote Neurospora. Evolution 57: 2703-2720.

Geurber JC, Correll JC (2001) Characterization of Glomerella acutata, the teleomorph of Colletotrichum acutatum. Mycologia 93: 216-229.

Gilligan CA (1983) Modeling of soilborne pathogens. Annual Review of Phytopathology 21: 45-64.

Guarnaccia V, Aiello D, Polizzi G, Perrone G, Stea G, et al. (2014) Emergence of prochloraz-resistant populations of Calonectria pauciramosa and Calonectria polizzii in ornamental nurseries of southern Italy. Plant Disease 98: 344-350.

Guindon S, Gascuel O (2003) A simple, fast, and accurate algorithm to estimate large phylogenies by maximum likelihood. Systematic Biology 52: 696-704.

Hillis DM, Bull JJ (1993) An empirical test of bootstrapping as a 
method for assessing confidence in phylogenetic analysis. Systematic Biology 42: 182-192.

Hwang SC, Ko WH (1976) Biology of conidia, ascospores, and microsclerotia of Calonectria crotalariae in soil. Phytopathology 66: 51-54.

Katho K, Standley DM (2013) MAFFT multiple sequence alignment software version 7 : improvements in performance and usability. Molecular Biology and Evolution 30: 772-780.

Kearse M, Moir R, Wilson A, Stones-Havas S, Cheung M, et al. (2012) Geneious Basic: an integrated and extendable desktop software platform for the organization and analysis of sequence data. Bioinformatics 28:1647-1649.

Li GQ, Chen SF, Wu ZH, Zhou XD, Xie YJ (2014a) Preliminary analyses on diversity and pathogenicity of Calonectria spp. on Eucalyptus in China. Chinese Journal of Tropical Crops 35: 1183-1191. [In Chinese]

Li GQ, Li JQ, Liu FF, Li TH, Chen SF (2014b) Preliminary analyses on pathogenicity of twelve Calonectria spp. on ten Eucalyptus clones in China. Eucalypt Science \& Technology 31: 1-7. [In Chinese]

Lombard L, Crous PW, Wingfield BD, Wingfield MJ (2010a) Species concepts in Calonectria (Cylindrocladium). Studies in Mycology 66: 1-14.

Lombard L, Crous PW, Wingfield BD, Wingfield MJ (2010b) Multigene phylogeny and mating tests reveal three cryptic species related to Calonectria pauciramosa. Studies in Mycology. 66: 15-30.

Lombard L, Crous PW, Wingfield BD, Wingfield MJ (2010c) Phylogeny and systematics of the genus Calonectria. Studies in Mycology 66: 31-69.

Lombard L, Zhou XD, Crous PW, Wingfield BD, Wingfield MJ (2010d) Calonectria species associated with cutting rot of Eucalyptus. Persoonia 24: 1-11.

Lombard L, Chen SF, Mou X, Zhou XD, Crous PW, et al. (2015) New species, hyper-diversity and potential importance of Calonectria spp. from Eucalyptus in South China. Studies in Mycology 80: 151-188.

Lombard L, Wingfield MJ, Alfenas AC, Crous PW (2016) The forgotten Calonectria collection: pouring old wine into new bags. Studies in Mycology 85: 159-198.

Marin-Felix Y, Groenewald JZ, Cai L, Chen Q, Marincowitz S, et al. (2017) Genera of phytopathogenic fungi: GOPHY 1. Studies in Mycology 86: 99-216.
Nirenberg HI (1981) A simplified method for identifying Fusarium spp. occurring on wheat. Canadian Journal of Botany 59: 1599-1609.

Ogden TH, Rosenberg MS (2007) How should gaps be treated in parsimony? A comparison of approaches using simulation. Molecular Phylogenetics and Evolution 42: 817-826.

Posada D (2008) jModelTest: phylogenetic model averaging. Molecular biology and Evolution 25: 1253-1256.

Rayner RW (1970) A Mycological Colour Chart. Kew: Commonwealth Mycological Institute.

Rodas CA, Lombard L, Gryzenhout M, Slippers B, Wingfield MJ (2005) Cylindrocladium blight of. Eucalyptus grandis in Colombia. Australasian Plant Pathology 34: 143-149.

Schoch CL, Crous PW, Wingfield MJ, Wingfield BD (2000) Phylogeny of Calonectria and selected hypocrealean genera with cylindrical macroconidia. Studies in Mycology 45: 45-62.

Swofford DL (2003) PAUP*: phylogenetic analysis using parsimony (*and other methods). Version 4. Sunderland, MA: Sinauer Associates.

Tamura K, Stecher G, Peterson D, Filipski A, Sudhir Kumar (2013) MEGA6: Molecular evolutionary genetics analysis version 6.0. Molecular Biology and Evolution 30: 2725-2729.

Thies WG, Patton RF (1970) The biology of Cylindrocladium scoparium in Wisconsin forest tree nurseries. Phytopathology 60: 1662-1668.

Van Burik JAH, Schreckhise RW, White TC, Bowden RA, Myerson D (1988) Comparison of six extraction techniques for isolation of DNA from filamentous fungi. Medical Mycology 36: 299-303.

Xu JJ, Qin SY, Hao YY, Ren J, Tan P, et al. (2012) A new species of Calonectria causing leaf disease of water lily in China. Mycotaxon 122: $177-185$.

Zhou XD, De Beer ZW, Xie YJ, Pegg GS, Wingfield MJ (2007) DNAbased identification of Quambalaria pitereka causing severe leaf blight of Corymbia citriodora in China. Fungal Diversity 25: 245-254.

Zhou XD, Xie YJ, Chen SF, Wingfield MJ (2008) Diseases of eucalypt plantations in China: challenges and opportunities. Fungal Diversity 32: 1-7. 